Elsevier Editorial System(tm) for Progress in Oceanography

Manuscript Draft

Manuscript Number: PROOCE-D-13-00096R1

Title: Intra-seasonal variability of the Deep Western Boundary Current in the western subpolar North Atlantic

Article Type: SI: North Atlantic Polar [IG005269]

Keywords: Deep Western Boundary Current

Western Subpolar North Atlantic

North Atlantic Deep Water

Current Meter Arrays

Deep Circulation

Labrador and Irminger Seas

Corresponding Author: Dr. Jürgen Fischer, Ph.D.

Corresponding Author's Institution: GEOMAR Kiel

First Author: Jürgen Fischer, Ph.D.

Order of Authors: Jürgen Fischer, Ph.D.; Johannes Karstensen, Dr.; Rainer Zantopp; Martin Visbeck, Prof. Dr.; Arne Biastoch, Prof. Dr.; Erik Behrens; Claus Böning, Prof. Dr.; Detlef Quadfasel, Prof. Dr.; Kerstin Jochumsen, Dr.; Hedinn Valdimarsson, Dr.; Steingrímur Jónsson, Dr.; Holliday P Naomi, Dr.; Bacon Sheldon, Dr.; Stephen Dye, Dr.; Monika Rhein, Prof. Dr.; Christian Mertens, Dr.

Abstract: Abstract

The Deep Western Boundary Current (DWBC) along the western margin of the subpolar North Atlantic is an important component of the deep limb of the Meridional Overturning near its northern origins. A network of moored arrays from Denmark Strait to the tail of the Grand Banks has been installed for almost two decades to observe the boundary currents and transports of North Atlantic Deep Water as part of an internationally coordinated Observatory for the Atlantic Meridional Overturning Circulation. The dominant variability in all of the moored velocity time series is in the week-to-month period range. While the temporal characteristics of this variability changes only gradually between Denmark Strait and Flemish Cap, a broad band of longer term variability is present farther along the path of the DWBC at the Grand Banks and in the interior basins (Labrador and Irminger Seas). The vigorous intraseasonal variability may well mask possible interannual to decadal variability that is typically an order of magnitude smaller than the high-frequency fluctuations. Here, the intra-seasonal variability at key positions along the DWBC path using both, observations and high resolution model data is quantified. The results are used to evaluate the model circulation, and in turn the model is used to relate the discrete measurements to the overall pattern of the subpolar circulation. Topographic waves are found to be trapped by the steep topography all around the western basins, the Labrador and Irminger Seas. In the Labrador Sea, the high intra-seasonal variability of the boundary current regime is separated by a region of extremely low variability in narrow recirculation cells from the basin interior. There, the variability is also on intra-seasonal timescales, but at much longer periods around 50 days. 



\section{GEOMAR}

Helmholtz-Zentrum für Ozeanforschung Kiel

GEOMAR | Düsternbrooker Weg 20 | 24105 Kiel | Germany

Progress in Oceanography

\author{
Dr. Jürgen Fischer \\ Physical Oceanography \\ Tel +49431600-4106 \\ Fax +49 431 600-4102 \\ jfischer@geomar.de
}

2. Dezember 2013

\section{GEOMAR}

Helmholtz-Zentrum für

Ozeanforschung Kiel

Düsternbrooker Weg 20

24105 Kiel | Germany

Tel +49 $431600-0$

$\mathrm{Fax}+49431$ 600-2805

www.geomar.de

Deutsche Bank AG Kiel

BLZ 21070024

Kto. 1448000

SWIFT/BIC DEUTDEDB210

IBAN DE 69210700240144800000

1) Manuscript

2) Figure Source Files

Steuernummer 1929404751

VAT DE281295378

3) Tables Source Files

2) A detailed response to each of the reviews (3 reviewers)

3) Highlights

Sincerely yours, Jürgen Fischer 


\section{Our response to reviewer \#2}

We would like to thank reviewer \#2 for his/her very careful evaluation of our manuscript, the constructive criticism and the recommendations for corrections and suggestions.

Below, recommendations by the reviewer are in blue and our response in black.

Review of "Intra-seasonal variability of the Deep Western Boundary Current in the western subpolar North Atlantic", Manuscript Number: PROOCE-D-13-00096

\section{General comments:}

Using long current meter records in the western margin of the subpolar gyre, the authors investigate the intra-seasonal variability in the Deep Western Boundary Current.

From the Denmark Strait to the Grand Banks they show - that the dominant variability is in the week-to-month period range - that 10 day periods dominate the variance, which they attribute to topographic Rossby waves - that at Flemish Cap and farther south, there is also variability at longer periods - that in the basin centers (Labrador and Irminger) the variance dominate at 50 day period and there is almost no variance at 10 days. Using a long time series in the DWBC at $53^{\circ} \mathrm{N}$ they also find seasonality in the intra-seasonal variability, with an offset of 6 months between the surface and the bottom.

Then to validate a new high resolution model, in order to use it to relate local observations to the larger scale environment, they compare the model intra-seasonal variability at the same locations as the observations. In order to argue about the existence of topographic waves they extract the AR7W section from the model, along which they calculate the EKE, the ellipticity of the variance ellipsoid and performed spectral analysis at the surface and $1000 \mathrm{~m}$ depth. Finally, they discuss of the accuracy of the estimates of long term fluxes controlled by the intra-seasonal energy peak.

My feeling is that it was a good idea to investigate and try to relate this intra-seasonal variability all around the subpolar gyre, by using local observations and a model. But I find this paper too descriptive and badly presented (quite messy). Besides a better presentation (we hope we improved that and it appears not as messy as before), the reader needs more elements to believe the conclusions.

\section{My main criticisms are:}

Most results of this paper come from spectral analysis.

Right, we now included variance ellipses and their variation to support the results.

But we don't know which method is used to compute the spectra, what is their significance;

We computed the spectra by using the Matlab statistics toolbox - PSD was calculated, using the Welch method with partitioning and tapering (Hamming window) data subsets of $128 \mathrm{~d}$ duration and subsequent overlapping segments of $50 \%$ or $64 \mathrm{~d}$. Then the spectra were ensemble averaged and presented in their variance conserving representation. This is now described in more detail in the text.

spectra are hard to compare, too small, with different $\mathrm{x}$-axis and often with no vertical lines to illustrate the same main frequencies.

This has been done now, and they are much better to interpret.

The authors conclude "Variability characteristics captured by high resolution model simulation", but I am far to be convinced by the spectral comparison of intra-seasonal variance (figure 13). From this point, it was difficult to adhere to the work done with the model. 
We agree that the level of variance in model and observation reveal significant differences, at least in some places. The model shows high frequency variance with frequencies in the same range (10 to 30 days. This is now more carefully discussed. Spectra are now better visible and guiding lines are included as requested.

The authors conclude "Topographic waves near 10d periods trapped over steep topography", but I find the demonstration too descriptive, although they have a lot of long time series from observations and model to analyze.

We include an analysis based on the variance orientation at $53^{\circ} \mathrm{N}$ (new figure 16 and 17). At $53^{\circ} \mathrm{N}$ is the only array that has stations on the slope and at the transition between slope and abyssal plain. When approaching the abyssal plain the 10-20d variance vanishes and longer periods begin to dominate the variance pattern. Variance ellipses in the near bottom layers (lowest 500m of the water column) are oriented along the topography for stations on the slope. At the transition, near bottom variance ellipses become more circular. Another interesting feature is the rotation of the variance ellipses from near bottom to the surface. About 1000-1500m above the bottom (i.e., half the water depth in the center of the DWBC), the variance is distributed almost circular, and higher up the axes rotate farther and the main variance axis is almost perpendicular to the near bottom layers. This is summarized in the text and supported by Figure 17. For comparison we also added the same product from the model (also 60d high pass filtered data). The model ellipses appear more elongated and topography controlled, even higher up in the water column. However, in the deep basin the ellipticity is smaller, but the variance is larger.

For comparison we included variance ellipses (Figure 17) of the intra-seasonal fluctuations in the model (also high pass filtered at 60d cut-off). Despite the lower amplitude of the variance, the ellipses are much stronger tied to the topography with significantly larger ellipticity compared to the observations. The near bottom variance is larger toward the basin interior and ellipticity becomes smaller.

This is now included in section 4.3.

Please note: former Figure 16 is now figure 18.

\section{Comments throughout the text:}

Page 4, §2.1: "The current vectors were rotated ... the principal axis of the variance (to be discussed later)" it could be interesting here, or page 15, to show the variance ellipses of the deepest current meters on a bathymetric map.

This is a very good suggestion and we included variance ellipses right in Figure 1 and in Figure 17, 18 for model and observations at the $53^{\circ} \mathrm{N}$ array (see the discussion above).

Page 4, §2.2: "overlapping segments (128 days long, 64-day overlap) ": which method do you use? Could you tell more about this point? Farther in the text you say that "individual spectra where ensemble-averaged": what spectra? What is the difference with the overlapping segments? What about confidence intervals or error bars?

This has been extended now, also according to Rev. 3

Page 5, §2.3.1: "Spectral analysis (Figure 4b) ": for all the spectra choose vertical lines to illustrate the same main periods $(5 \mathrm{~d}, 10 \mathrm{~d}, 30 \mathrm{~d}, 100 \mathrm{~d}$ for example); keep the same $\mathrm{x}$-axis limits (1d-150d for example). The spectra will be easier to compare. You are only interested in intraseasonal variability, so why don't you average the three spectra on this figure $4 \mathrm{~b}$ ?

We followed the suggestion and included orientation lines and identical $\mathrm{x}$-axes for all spectra where possible. 
Page 5, §2.3.1: "This peak is found at very short periods and the energy increase at periods of 5-10 d may be associated with the very small Rossby radii of this area. " What do you mean? Develop or delete.

We removed that sentence and instead added a citation (Smith 1976) that identifies baroclinic instability of the overflow plume as a reason for the high frequency variability with the most unstable wave at periods of just 2-3 days.

Page 6, §2.3.2:"The spectral decay to longer periods is strong and makes this location favorable for determining longer term variability as the intra-seasonal variance could be separated (filtered) effectively from the long term (interannual to decadal) time scales. ": so what?

As this is part of a misplaced discussion we removed that at this place and now have an extended discussion If the variance decay as a function of time scale is faster than the reduction of the degrees of freedom, then a spectral gap allows to remove most of the noise and the low frequency current/transport fluctuations can be determined more accurately.

Page 6, §2.3.3, Figure 6a uses the results of IFREMER moorings, described in Daniault et al., JPO 2011 (doi: 10,1175/2010JPO4428.1). In this paper, it is interesting to note that a spectral analysis shows that a peak energy is observed at about 10-day period at all depths on the slope.

$\mathrm{R} 2$ objected to the sentence on $\mathrm{p} 7$ where we say the spectra at mid-depths are dominated by 2 4 day variability. This information is taken from an unpublished draft manuscript led by Saunders. The 2-4 day variability was found in a mooring close to the seafloor at $1629 \mathrm{~m}$, which is right on the upper limit of the plume of dense water of the DWBC, and comes from an IFREMER EGC data set, rather than the NOC DWBC data set. This is why it does not show in the Fig 6 spectra. We removed that sentence and instead added the Daniault (2011) paper.

Page 7, §2.3.4: "All moorings were at least partly within the deep boundary current and reveal a similar frequency distribution of deep variability (Figure 7b)".: K9 does not show a peak at about 50 days (right panel of figure $7 b$ ).

This has been reformulated for improved clarity.

"variance levels of the DWBC increase with depth" : I don't see that? But the spectra are very small, and it is hard to see something. Please, give numbers.

Will be supported by both, better figures and numbers, e.g. by the new Figures 16 and 17 .

Page 9, §2.3.5: "This has immediate consequences for the investigation of longer term variability, as the number of degrees of freedom...": to emphasize this point and to add substance at the third point of the summary ( $\$ 5)$, I suggest to summarize in a table the mean, the variance, the integral time scale, the number of degrees of freedom, and the statistic error on the mean, for all the current meters lying in the DWBC.

Right, this is a very valuable recommendation and we include such a table and discuss it near the end of the paper. This should also smooth some of the "messy" structure of the manuscript. 
Page 9, §2.3.6:"uncertainties (the number of degrees of freedom, NDF, are smaller) are larger than farther up north": it will be easier to discuss with the table mentioned previously.

Will be visible in the new table and is discussed in summary and discussion.

Page 12, §4.1, figure 12:"The model spectra from 50m above the bottom": why don't put near bottom spectra of K8, K9 and $\mathrm{K} 10$ on the right panel in order to compare observations and model?

"this may partly be caused by the much longer observations compared to the 2-years of model data": you could check that by taking only two years of observations?

Right, we changed the figure accordingly, and find it more illustrating for the differences in the frequency distribution.

Figure 13: "When we follow the path of the DWBC and compare model and observational spectra of the near bottom flow": I find hard to see any resemblance between the spectra. "If we look into the records of Angmagssalik ,... then the first thing to note is the complex structure of the topography...": the topography is steeper at other locations along the DWBC path; could you show the model topography compared to the observations topography? I don't see any seasonal cycle with the 128-day cut-off period.

This has been reworked as recommended (of course, 128d spectra could not reveal seasonal cycles - those were visible in the model time series (now clarified)).

"To illustrate the consequence for estimating long...": paragraph misplaced. This is an example of what I mean by "messy".

This has been removed here and is now part of the summary and discussion section.

"Summarizing, the model reveals variance maxima at frequencies similar to the observed ones": it is hard to see anything on this figure which however is the heart of the paper. I can't agree with this affirmation. I kept reading, but it was tempting to stop here.

With the new analysis of the structure of the variance ellipses we agree with the reviewers comment, in that the model differs in some respects considerably from the observations. The message has been altered accordingly and we reorganized the 'messy' part.

Page 13, §4.2:"Spectral energy in the central Labrador Sea ... but the frequency distribution is very different": do you mean variability intensity instead of spectral energy?

Yes, we compare overall variance (see new table).

What about the model spectra in the center of the basins? Isn't it better than at the boundaries? That is a good question, and we added the model spectrum at K1 location and in the Irminger Sea and discussed these accordingly)

Page 14, §4.3, Figure 15: could you adjust vertically the $\mathrm{x}$ axis (distance) of the three panels? Or is there a mistake in the labels? The steep topography around $400 \mathrm{~km}$, where the DWBC is flowing, corresponds to the low energy region?

This has been corrected now.

Page 15, §4.3:all this paragraph about topographic Rossby waves is very descriptive; you have a lot of long time series (from observations and model) at key points of the DWBC path. It could be interesting, as in Fratantoni et al., (2003) to compute and compare the lagged 
correlation between neighboring near-bottom instruments (observations) and/or neighboring near-bottom points of the model.

In the course of the summary and discussion and the new discussion on orientation of the variance ellipses this para has been reorganized with a somewhat extended discussion on TRW's. A formal Lag correlation along the bottom has been made but the results were not encouraging. Additionally the principal axes of the variance ellipses are not consistent between model and observations - see Figures 16 and 17.

Page 16, §4.4, Figure 17:"At depth, the maximum intra-seasonal variance is in summer": I see the maximum around September, October $(9,10)$ ? Right, we changed that to 'fall'.

Page 17, §5:"Verification of the high frequency variability represented in a high resolution model through moored observations ": I am still not convinced.

We agree that verification may be the wrong wording, it is more a comparison -- changed that accordingly

Page 17, §5:"how accurate are our estimates of deep water transports": if you summarize in a table the mean, the variance, the integral time scale, the number of degrees of freedom, and the statistic error on the mean, for all the current meters lying in the DWBC, this discussion would be improved.

This table (Table 2) is requested at various places and we added such a table for statistics of each of the arrays (one typical value for array center) and discuss this accordingly. We also included the topographic slopes and the ratio of the total vs. the intra-seasonal (60day high pass filtered) data.

The result shows that the estimated errors of e.g. annual mean flow will be larger when the frequency of the boundary current variability is lower.

3 Minor comments: (Thank you, we followed all recommendations in this category) page 2: EU = European Union

page 5, 4th paragraph: "of the of the near-bottom"

page $6, \S 2.3 .2$, last line: "effectively form the long term": from

page $10 \S 3$ ( and bibliography): Blanke and Delecluise,1993: Delecluse

page 14: "the WOCE AR7W- section section"

page 14: "week recirculation cells": weak

page 21: Xu, X., H.E. Hurlburt ... 2013, pages 502-516. (wrong year and page numbers)

page 22, Figure 3: "Ensemble averaged spectra from 128 day long subsamples as red lines.":

no red lines.

Figure 6a:It is not clear what is the deepest instrument (1 or 2)?

Figure 8: it is better to name B22 and B23 moorings on figure 8a 


\section{Our response to reviewer \#3}

We would like to thank reviewer \#1 for his/her very positive evaluation of our manuscript, the constructive criticism and the very careful corrections and suggestions.

Below, recommendations by the reviewer are in blue and our response in black. We generally followed the recommendations.

These authors report on results from an admirable accomplishment -- the task of maintaining over the past two decades a network of current meter moorings at six transects across the Deep Western Boundary Current located between the Denmark Strait and the southern tip of the Grand Banks. They have selected only current meters at near-bottom depths such that the density exceeds $27.8 \mathrm{~kg} / \mathrm{m}^{\wedge} 3$ so that they are within the Northeast Atlantic Deep Water and below the Labrador Sea Water, and thus part of the unventilated DWBC. The lengths of their time series are all at least 3 years, and the longest three sets span 15, 16, and 26 years. This article focuses on the dominant variability in the moored current time series, which occurs at periodicities from a week to a few months, i.e. intra-seasonal.

Despite the diversity of institutions and people and year and measurements, they have achieved a remarkable degree of uniformity in the analyses (e.g., $128 \mathrm{~d}$ ensemble-averaged spectra) and discussions. Imperfect uniformity of plots and emphases, etc., but presented and summarized in an understandable format.

The "highlights" listed (next to five bullets) capture their findings well.

The model comparisons, while quite limited, suggest useful metrics by which these and future model comparisons might be judged. And they support the concept that resolution of bottom topography seems to be a key factor for successful model performance.

Question: All arrays except Cape Farewell had a neighboring array in place during some of their measurement interval, which would allow investigation of whether any along-boundary coherence can be observed between neighbors? If the authors tried this and found insignificant coherence, even that would be useful to state.

The spreading of anomalies along the boundary has been discussed for quite a while for both, the spreading of thermohaline anomalies (e.g. Stramma et al. 2004) and current fluctuations. On long time scales T/S-anomalies can be followed, but current anomalies are masked by high frequency current variability that has short spatial scales (generally less than the distance between the mooring arrays). This variability is so energetic that it appears to mask any possible coherent current structure on longer time- and space- scales. We mentioned this in the ms now on Page 18.

p.2 THOR is listed with a "?" after it on p.5, but without it here. Should make it consistent. THOR throughout now

p.4, Sec 2.2. Make the terminology more precise in line 3-4. Replace "... were used to estimate the energy conserving version of the variance spectra; thus..."

with

"...were used to estimate ensemble-averaged spectra (S) and plot these in variance-conserving form (fS vs. $\log (\mathrm{f})$ ); thus..."

This has been done now and a more thorough description of the spectral analysis is included on page 4 . 
p.5, bottom. You might choose to suggest that the energetic 5-10 d variability may be partly driven non-locally by atmospheric forcing, such as atmospheric pressure fluctuations north of the sill. Or offer explanation why short Rossby radii would favor energy increase at periods of 5-10 d.

We changed this to:

This has been in the focus since many years, and e.g. Smith, 1976 found baroclinic instabilities of the overflow plume at periods as low as $2.1 \mathrm{~d}$ for the most unstable wave.

p.6, last line of Sec 2.3.2. change "form" to "from" done

p.7, top paragraph. The example of dominant 2-4 day variability in the DWBC at mid-depths (cited as Saunders pers. comm.) is so very different than anything shown in this paper contradictory it seems -- that it demands further explanation.

It would help to show the spectra and location and discuss why it is so different.

Both reviewers objected to the sentence on $\mathrm{p} 7$ where we said the spectra at mid-depths were dominated by 2-4 day variability. This information is taken from an unpublished draft manuscript led by Saunders. The 2-4 day variability was found in a mooring close to the seafloor at $1629 \mathrm{~m}$, which is right on the upper limit of the plume of dense water of the DWBC, and comes from an IFREMER EGC data set, rather than the NOC DWBC data set. This is why it does not show in the Fig 6 spectra. We removed hat sentence instead added the Daniault, 2011 paper.

p.8, Sec 2.3.5, paragraph 2. Because TRWs are the dominant variability, with variable currents large enough to flow in reverse of the mean for a few days (fig 9),

no conclusion can be drawn about the lateral structure and position of the current based on a snapshot shipboard lowered ADCP section. The claim is unsubstantiated and should be removed that the moored array captured some known fraction like $2 / 3$ of the total southward transport.

Ok, the reviewer is right and we removed that sentence.

p.13 top. The sentence "Quantitatively ... noise level of $+/-3 \mathrm{~cm} / \mathrm{s}$," is not useful without discussion of time scales and degrees of freedom. The authors present that information later, in the final paragraph of the Summary. So move it all together in one place and delete it from the other.

This is now covered in the discussion and a new table with these parameters is included.

p.15, line 5. Clarify "...information is spreading faster along..." regarding what information and faster than what?

Due to improved representation of the bottom topography by partially filled cells (also used in VIKING20), circulation changes communicated by topographic waves are simulated more realistically.

p.16, last par. "... the maximum intra-seasonal variance is in summer..." Fig 17 indicates maximum in Sept-Oct-Nov, not "summer." 
Right, is changed to "fall to winter". Also noted by R2. This figure is now Figure 19.

p.17 5th bullet, change "week" to "weak"

done

7th bullet - make it a complete sentence like the other six bullets.

Moored observations are used to verify the representation of the high frequency variability in a high resolution model

Fig 4 define bold black line

Black line in Fig 4 a is: $\sigma_{\theta}=27.8 \mathrm{kgm}^{-3}$

Fig 8. In this caption restate length of time series ( $3 \mathrm{yr}$ ?), like in other captions.

done

Fig 12, left panel - label what depths are being compared?

Fig 12 changed in response to recommendation of all reviewers; Figure 12 has been altered to near bottom comparison of model and observations with depth information included now.

Fig 16. The locations of these two sections should be shown, e.g. on maps of Fig 1 or Fig 11.

Has been done in Figure 1, together with the variance ellipses recommended by R2, crossreference is given in figure caption. Figure 16 has become now figure 18 . 
Our response to reviewer \#4

We would like to thank reviewer \#4 for his/her positive evaluation of our manuscript, the constructive criticism and the recommendations for corrections and suggestions. Below, recommendations by the reviewer are in blue and our response in black. We generally agreed with the recommendations and changed the ms accordingly.

I think this is a very good paper. The authors use current meter data collected along the North Atlantic's DWBC during the last 20 years or so to evaluate the variability of the current and its connectivity between Denmark Straits and the Grand Banks of Newfoundland. This research is timely given the new impetus that existing research on the ocean dynamics and climate of the subpolar gyre will receive once the international OSNAP and Canadian VITALS programmes begin in earnest. My sole major recommendation is that the authors include a short section (or long paragraph) describing and discussing the observed and modelled mean flow, its strength and its spatial distribution both vertically and along the DWBC. The measured mean flow is only shown for the Cape Farewell data, while fullcurrent time series are also included in the figures of K9 and K18. I think it would be appropriate to provide a brief comparison of the means of these fields before embarking on the

analysis discussion of the variability. The paper is very clearly written and very readable.

The main point that Reviewer \#4 raises is a brief description of the mean appearance of the DWBC in both model and observations. In fact, the introductory figures of the different arrays with full ocean depth arrays (Cape Farewell and Labrador Sea arrays) have a component showing the Boundary Current flow structure from either the current meter moorings or other direct current observations. In addition we extended the short description of the modelled boundary current flow when we introduce the model data.

Page 3. Give the reference pressure/depth for $\langle$ sigma $\rangle\langle$ theta $\rangle$.

Done -- relative to surface pressure

Page 4. "The current vectors were rotated". Do you mean "projected"?

$\mathrm{Ok}$ - projected is the better wording

Page 5. "of the of the"

done

Page 9. "father north"

Done, farther north

Page 10. "approach.,"

done

Page 13. "can been"

done

Figure 6. Positive means southwards.

Right, positive is approximately southward

Figure 12. Left panel. What are the model depths for these three curves?

Instruments from 50m above bottom - similarly for the model data (lowest cell above bottom). 
Highlights:

- A joint analysis of deep current meter records in the western North Atlantic

- Intra-seasonal variability dominates the deep boundary current

- $\quad$ Topographic waves near $10 d$ periods trapped over steep topography

- Basin centers are showing longer periods (50d) caused by the eddy field

- Observed variability characteristics compared to high resolution model simulation. 


\title{
Intra-seasonal variability of the DWBC in the western subpolar North Atlantic
}

Fischer $^{\mathrm{a}}$, J., J. Karstensen ${ }^{\mathrm{a}}$, R. Zantopp ${ }^{\mathrm{a}}$, M. Visbeck ${ }^{\mathrm{a}}$, A. Biastoch ${ }^{\mathrm{a}}$, E. Behrens ${ }^{\mathrm{a}}$, C. W. Böning $^{\text {a }}$, D. Quadfasel ${ }^{\mathrm{b}}$, K. Jochumsen ${ }^{\mathrm{b}}$, H. Valdimarsson ${ }^{\mathrm{c}}$, S. Jónsson ${ }^{\mathrm{g}}$, S. Bacon ${ }^{\mathrm{d}}$, N. P.

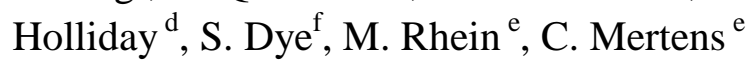

${ }^{a}$ GEOMAR Helmholtz Centre for Ocean Research, Kiel, Germany

${ }^{\mathrm{b}}$ ZMAW Zentrum für Marine und Atmosphärische Wissenschaften, Hamburg, Germany

c Marine Research Institute, Reykjavik, Iceland

${ }^{\mathrm{d}}$ National Oceanography Centre (NOC), Southampton, UK

${ }^{\mathrm{e}}$ Institut für Umweltphysik, Universität Bremen, Germany

${ }^{\mathrm{f}}$ CEFAS Centre for Environment, Fisheries and Aquaculture Science, Lowestoft, UK

${ }^{\mathrm{g}}$ University of Akureyri and Marine Research Institute, Iceland

\begin{abstract}
The Deep Western Boundary Current (DWBC) along the western margin of the subpolar North Atlantic is an important component of the deep limb of the Meridional Overturning near its northern origins. A network of moored arrays from Denmark Strait to the tail of the Grand Banks has been installed for almost two decades to observe the boundary currents and transports of North Atlantic Deep Water as part of an internationally coordinated observatory for the Atlantic Meridional Overturning Circulation.

The dominant variability in all of the moored velocity time series is in the week-to-month period range. While the temporal characteristics of this variability change only gradually between Denmark Strait and Flemish Cap, a broad band of longer term variability is present farther along the path of the DWBC at the Grand Banks and in the interior basins (Labrador and Irminger Seas). The vigorous intra-seasonal variability may well mask possible interannual to decadal variability that is typically an order of magnitude smaller than the highfrequency fluctuations. Here, the intra-seasonal variability is quantified at key positions along the DWBC path using both, observations and high resolution model data. The results are used to evaluate the model circulation, and in turn the model is used to relate the discrete measurements to the overall pattern of the subpolar circulation. Topographic waves are found to be trapped by the steep topography all around the western basins, the Labrador and
\end{abstract}


Irminger Seas. In the Labrador Sea, the high intra-seasonal variability of the boundary current

\section{1) Introduction and objectives}

A joint observational and modeling effort coordinated and temporarily supported by the European Union (EU) named THOR (Thermohaline Overturning at Risk) and with additional support from other national projects (e.g., the German North Atlantic and RACE programs) with a focus on western boundary current intensity, variability, and change has been undertaken in the subpolar North Atlantic over most of the last two decades.

The focus of this paper is on a comparative analysis of intra-seasonal variability along the Deep Western Boundary Current (DWBC) beginning shortly after exiting the subarctic regime at Denmark Strait (Macrander et al., 2007, Jochumsen et al., 2012). The investigation (Figure 1) follows the path of the DWBC along the East Greenland shelf break with the Angmagssalik array (Dickson et al., 2008), and toward the southern tip of Greenland and the Cape Farewell array (Bacon and Saunders, 2010). The Cape Farewell region appears to be a region with a complex deep circulation, including recirculating pathways (Holliday et al., 2009).

From Cape Farewell, the DWBC then travels around the Labrador Sea as the deep part of the West Greenland Current, passing through the $53^{\circ} \mathrm{N}$ array (Fischer et al., 2010, Dengler et al., 2006) off southern Labrador in the Deep Labrador Current (DLC) and entering the open subpolar North Atlantic at Flemish Cap (Rhein et al., 2011) and finally (for this investigation) exits the subpolar regime at the tail of the Grand Banks (Schott et al., 2004, 2006). Besides the DWBC there also are interior routes along which North Atlantic Deep Water (NADW) either recirculates in the subpolar basin or is exported into the subtropics (Bower et al., 2009). However, in a comparative analysis of the currents and transports in a high resolution $\left(0.08^{\circ}\right.$ grid) isopycnic HYCOM model, Xu et al. (2013) show that the boundary flow at $53^{\circ} \mathrm{N}$ is correlated with the Meridional Overturning Circulation (MOC) transport across WOCE Line AR19 off the Grand Banks, and in an earlier study by Böning et al. (2006) it has been shown that the deep water export from the Labrador Sea is correlated with the mid-latitude Meridional Overturning Circulation (MOC). Toward the North, Bacon and Saunders (2010) discussed the deep boundary transport variations on long (decadal) time scales. By estimating the accuracy of the transports at Cape Farewell, they found that present-day transports were significantly weaker (30\%) than in the 1970s. The older transport estimates correspond to what has been measured off Labrador $\left(53^{\circ} \mathrm{N}\right.$ array; Fischer et al., 2010) with only minor (insignificant) changes over the last 12 years. 
The intraseasonal variability of the DWBC has been investigated in various publications, in particular for the region south of the Grand Banks, off Cape Hatteras, and was related to topographic waves. The variability is strong and may mask the mean flow of the DWBC. Based on the analysis of mooring arrays (e.g. Pickart and Watts, 1990) as well as from single moorings (e.g. Thompson and Luyten, 1976) the highest energy was found at about 40 days, characteristic of fluctuations associated with topographic Rossby Waves (TRW). For the Cape Hatteras region, the frequencies are consistent with remote forcing through meandering of the Gulf Stream as well as interaction of the Gulf Stream with rings (see Pickard and Watts, 1990).

The objectives of this study are:

- Determination and comparison of the observed intra-seasonal variability of the subpolar DWBC.

- Discussion of regional differences in the intra-seasonal variability - relating discrete, local observations to the large scale distribution from high resolution modeling.

- How is intra-seasonal variability represented in a present day high resolution model VIKING20?

- What are the consequences of this variability on determining the spreading of circulation anomalies?

- What consequences do intra-seasonal fluctuations have on uncertainties of boundary current transports as derived from limited observations?

- What are the physics behind those fluctuations?

The outline of the paper is as follows: we first describe how individual current records are treated to obtain a comparable data base for all the different mooring efforts in the western subpolar North Atlantic. Then we present an overview of the present and past observational efforts, namely location and structure of the individual current meter arrays. We explain why the arrays have been placed where they are, and what their present day status is. In each of the sections we then describe the deep intra-seasonal variability in terms of spectral decomposition and variance analysis.

Thereafter, we briefly introduce the model data, key model parameters, and what has been done to generate products compatible with the observations. This will be followed by a discussion section in which regional aspects are discussed, including basin interior versus boundary current variability, and in which we will present a model - observation comparison for the various locations.

\section{2) The arrays, their metadata, and their deep intra-seasonal current variability}

From Denmark Strait to the tail of the Grand Banks, European groups have installed a series of current meter moorings during the previous decades. These moorings (see Figure 1 and Table 1) were mainly organized in arrays that cover parts or all of the DWBC. Most of the data are already published, some are just recently measured, but they have never been analyzed in a coherent and systematic context. Individual records are different in many 
respects - e.g., their length and location. Here we select only those data that were measured at densities (relative to surface pressure) larger than $\sigma_{\theta}=27.80 \mathrm{kgm}^{-3}$, meaning that we concentrate on currents found in the density range of the overflow components. Only in some cases we include data from shallower levels.

\subsection{Processing and selecting the data from observations and models}

As the mooring data were from different efforts and different nations, the processing of the data was somewhat different. Generally, the current meter data were de-tided (preferably by applying a 40-hour low pass filter) and subsampled at daily or half-daily resolution - for most data sets we applied this to the raw data rather than using a later processing stage by the originator. This procedure removes the most energetic tides and it is assumed that the remainder is dominated by longer term, but still sub-seasonal, variability (see time series of an example at $53^{\circ} \mathrm{N}$ in Figure 2). Here, we are interested in the variability on time scales up to a few months, as these appear to be the most energetic periods in the deep currents of the western subpolar North Atlantic.

Common to all records and locations is that we mainly compare velocity data from the density range $\sigma_{\theta}>27.80 \mathrm{kgm}^{-3}$. This isopycnal marks the transition of the North East Atlantic Deep Water (NEADW) to the Labrador Sea Water (LSW) above. The depth of this density surface varies along the DWBC from less than 1000 m north of the Angmagssalik array to more than $2000 \mathrm{~m}$ in the Grand Banks area. For this layer we were able to define boundaries (isopycnals), as these levels are not ventilated in the western SPNA during the last decade, and thus, long term modulation and the temporal variability at seasonal time scales is small. The current vectors were projected to the direction of the DWBC by either using the direction of the mean flow or the direction of the principal axis of the variance (see Figure 1; to be discussed later), both of them agree within a few degrees, and are largely parallel to the local isobaths.

\subsection{Intra-seasonal variability and spectra}

Along the DWBC, the most energetic variability in the respective array occurs in a period range of days to several weeks; i.e. much shorter than seasonal. In order to increase the significance of the spectra, overlapping segments (128 days long, 64-day overlap) of the time series were used to estimate the power spectral density. Spectra in this paper are derived by Welch's (Welch, 1967) method in the statistics package of the Matlab software, and it's the variance conserving representation that is used herein.

Briefly, the input current vector $U$ (alongshore speed) is divided into k overlapping segments according to the window width of $128 \mathrm{~d}$ and $50 \%$ overlap. The specified window (Hamming window) is applied to each segment of $U$, thus interrupted time series segments of at least 128 day length can be used. A Fast Fourier Transformation (FFT) is applied to the windowed data. The periodogram of each windowed segment is computed, and the resulting set of periodograms is averaged to form the spectrum estimate which results in the Power Spectral Density when divided by the sampling frequency (typically $1 /$ day or $2 /$ day. By this procedure we excluded seasonal modulations and longer term variability. 
The time series are seldom uninterrupted over several years, but in some of the arrays we have multiyear long segments and are able to perform a spectral analysis in the frequency range from weekly to multiannual periods (Figure 3). For better detection of dominant time scales and increasing significance, the individual spectra were ensemble-averaged (red lines in Figure 3). This is the procedure that we performed for all records presented here and also for the model investigation later on.

The full spectra shown here (Figure 3, blue lines) are from the longest segments of the central mooring (K9) in the Labrador Sea array at $53^{\circ} \mathrm{N}$. These raw (de-tided) spectra are relatively noisy, but allowed us to look at the long term variability in comparison to intra-seasonal periods. It is evident from Figure 3 that the variability on periods exceeding 100 days is small when compared to that of the 1-100 days band. However, we see a small seasonal peak, stronger near the surface than at the bottom, and there is almost no variability at timescales longer than a year. With regard to the origin of the intra-seasonal variability, previous investigations with a high resolution $1 / 12^{\circ}$ model (Eden and Boening, 2002; Morsdorf, pers. communication.) revealed that the intra-seasonal variability of the Boundary Current at the Labrador shelf break is mainly caused by baroclinic instability, while the West Greenland Current becomes barotropically unstable with a maximum during the high wind stress curl in winter.

\subsection{Array overview}

We provide a brief description of each array with meta information, but do not describe the mooring designs and deployments in detail. For all arrays, publications already exist that describe the location and data, and in most cases there are Deep Water transport numbers given as well. Hence, we restrict the introduction of the arrays to the information relevant for this study.

\subsubsection{The Denmark Strait Overflow Array}

The aim of the mooring array in Denmark Strait is to observe the overflow and its long term variability when it enters the Atlantic Ocean. Downstream of the sill, vigorous entrainment dilutes the properties of the overflow water and enhances the volume transport. Therefore, measurements directly at the sill are ideal to detect changes in the strength of the overflow.

The mooring program at Denmark Strait was initiated in 1996 by the Marine Research Institute in Iceland. In 1999, the University of Kiel contributed additional moorings in Denmark Strait. The results of a first 4-year period were published in Macrander et al. (2005). Since 2007, the moorings have been a joint effort of the University of Hamburg and the Marine Research Institute, Reykjavik in the framework of the European THOR (Thermohaline Overturning at Risk?) project, and the follow-up project NACLIM (North Atlantic Climate). 
The array consists of two upward looking moored ADCPs (both $75 \mathrm{kHz}$ instruments and 150 $\mathrm{kHz}$ instruments were used), with two SBE-37SM Microcats, mounted close to the bottom. The first bin measured by each ADCP is only $26 \mathrm{~m}$ above the sea floor. The temporal resolution of the measurements is 20 minutes, but to reduce uncertainties the data were averaged to hourly values. Overflow transports were determined by Macrander et al. (2007), and by Jochumsen et al. (2012). The two ADCPs were deemed sufficient for estimating the overflow transport (Dickson et al., 2008).

Attempts for an extension of the mooring array on the shelf were made during the first years of the array, but the region proved to be frequently visited by fishing vessels, and trawlresistant frames are needed to secure moored instruments in this region. Handling these frames is heavy work and they are more expensive than ordinary moorings. Therefore, only the two ADCP moorings in the deep part of the passage were in operation during the majority of the array deployment, which nevertheless cover the strongest signal (Figure 4a). Repeatedly taken shipboard ADCP sections extending onto the shelf confirmed the flow on the Greenland shelf to be weak. Some mooring losses occurred there as well and gaps in the transport time series resulted from these losses. Recently, the quality of the near-bottom measurements by the $75 \mathrm{kHz}$ ADCPs was found to be lower than those of the $150 \mathrm{kHz}$ data, hence only data from the $150 \mathrm{kHz}$ ADCP deployments were used in this study.

Spectral analysis (Figure 4b) has been performed on the ADCP current records from years 2007-08, and from 2009 - 2011. The intra-seasonal variance is very high at this location (as we will see later by comparison with the other locations) and it is here where the spectral peak lies around $200 \mathrm{~cm}^{2} \mathrm{~s}^{-2}$. This peak is found at very short periods and the energy increase at periods of 5-10 d. The origin of these fluctuations has been discussed already in 1976 by Smith as a consequence of the baroclinically unstable overflow plume. In a simple model Smith found that the most unstable wave is $80 \mathrm{~km}$ long at a period of $2.1 \mathrm{~d}$. Toward longer periods the variance is strongly decaying, and at $30 \mathrm{~d}$ periods the variance level is less than 50 $\mathrm{cm}^{2} \mathrm{~s}^{-2}$. Beside the $5 \mathrm{~d}$ peak, the overall maximum is located at 10 days, and it is this period that dominates the records at most of the stations.

\subsubsection{The Angmagssalik Current Meter Array}

The Angmagssalik Current Meter Array (Figures 1, 5) was initially funded in the mid-1980s (since 1995 as a full array) to monitor the core of the Denmark Strait overflow plume after it has completed the vigorous entrainment immediately downstream of the sill. The plume here is at depths between $1000 \mathrm{~m}$ and $2500 \mathrm{~m}$ in a bottom layer up to $300 \mathrm{~m}$ thick. This array is predominantly equipped with rotor current meters (Aanderaa RCM8), only very few acoustic current meters (RCM11 and Seaguard) were used in more recent years. The design of the array was altered repeatedly, especially on the steep and shallow slope, where most mooring losses occurred. The recent design is illustrated in Figure 5a. We only selected the records from moorings UK1 and UK2 as these are the longest records obtained at fixed positions and contained measurements in the chosen density range (Figure 5). 
The current meter time series of the Angmagssalik Array is one of the longest in the Atlantic, and therefore well suited to study the boundary current variability. Spectra of the core Denmark Strait overflow (DSOW) layer (mooring UK2 instruments at $2400-2200 \mathrm{~m}$ ) show a very pronounced peak at periods near 12 days (Figure 5b). However, spectral energy rises already at very short time scales, namely at $5 \mathrm{~d}$-periods.

The shorter record of UK1 upslope shows similar frequencies, with a variance maximum at 12 days, that has the same amplitude as observations farther down the slope, but this record shows an additional, even higher peak at 8d-periods. This is the second largest variance of all locations, exceeded only by the flow in Denmark Strait. At both locations (UK1 and UK2) the variance decreases toward the bottom. The spectral decay to longer periods is strong and makes this location favorable for determining longer term variability as the intra-seasonal variance could be separated (filtered) effectively from the long term (interannual to decadal) time scales.

2.3.3 The Cape Farewell Array The aim of the Cape Farewell array (Figure 6) was to measure the transport and variability of the DWBC just before it enters the Labrador Sea. The mooring array (Figure 6a) was deployed in September 2005, recovered and redeployed in August 2006, and finally recovered in September 2008 (Bacon, 2006a, Bacon 2006b, Bacon, 2010). The array was enhanced by a deployment by IFREMER of two further moorings inshore of the National Oceanography Centre (NOC) array, designed to measure the East Greenland Current, but not used in this study. From the combined array, the mean transport of water $<3.0^{\circ} \mathrm{C}$ was found to be $7.8 \pm 0.8 \mathrm{~Sv}$, and for $\sigma_{\theta}>27.80 \mathrm{~kg} \mathrm{~m}^{-3}$, the mean transport was 9.0 Sv (Bacon and Saunders, 2010).

All records (Figure 6b) show a high frequency variance maximum around 10 day periods, and thus, the deep water transport (Daniault et al., 2010) also exhibits this spectral shape; in that paper, the effect of the intra seasonal fluctuations on the accuracy of bi-annual mean transport was discussed. However, it is the deepest record in mooring B, located at $2450 \mathrm{~m}$ water depth that shows higher variance and a shift toward lower frequencies, with a peak near the $20 \mathrm{~d}$ period. This behavior of a more 'reddish' spectrum in the deeper basin will be investigated later.

\subsubsection{The $53^{\circ} \mathrm{N}$ Array off Labrador}

One of the areas of major importance for the formation and spreading of water masses in the Atlantic MOC (AMOC) is the Labrador Sea, characterized by a cyclonic (anticlockwise) boundary current surrounding one of the most active areas of water mass transformation in the world's ocean (Marshall and Schott, 1999). Along the Labrador shelf break, the three components of NADW merge into the DWBC as part of the cold water limb of the AMOC. Therefore, this location at $53^{\circ} \mathrm{N}$ is well suited to observe, and potentially monitor, long term changes of the outgoing component of those water masses which enter the North Atlantic from the Arctic Ocean.

Since summer 1997 (Fischer et al., 2004, 2010), the array was installed and serviced every other year (Figure 7a). However, the spatial station coverage has varied significantly, ranging 
from 5 moorings during the initial phase and during recent years to only one mooring in the

\subsubsection{The Flemish Cap Array at $47^{\circ} \mathrm{N}$}

The Flemish Cap mooring array (Figure 8) was installed with the aim of measuring strength and variability of the export of deep water from the subpolar North Atlantic and to compare the observed variability with measurements of the North Atlantic Current transport west of the Mid-Atlantic Ridge (Rhein et al., 2011).

The array consists of three current meter moorings, which initially were located directly at the continental slope of Flemish Cap near $47^{\circ} \mathrm{N}$. The moorings were first deployed in summer 2009 and serviced in summer 2010. After the second deployment period the easternmost mooring was lost during recovery. Shipboard measurements illustrate how the mooring array is located relative to a snapshot of the boundary circulation. A continuation of the array for at least three more years from 2012 onwards has been funded.

The topography at this location is steep, so that the DWBC is closely attached to the continental slope, with one mooring (B22) located directly in the velocity core of the DWBC (Fig. 8). The variance distribution is much more diverse compared to the more northerly ones. The time series are relatively short (about one year only) and thus, the significance of individual peaks is small. Besides the high frequency peak with less than 10d periodicity, the boundary current shows longer period variances that are not observed in the records discussed 8 
so far. Longer periods appear in the most offshore mooring B23, where the topographic slope

\subsubsection{The Grand Banks Array}

The farthest downstream location in the DWBC considered here, is the tail of the Grand Banks (Figure 1), a place where the WOCE Array ACM 6 (1993-95) was established by Canadian researchers (Bedford Institute of Oceanography, BIO) and continued by the IFMGEOMAR group in 1999 to 2005 (Schott et al. 2004, 2006). While the focus of ACM6 was on the warm water flow of the upper ocean, the continuation array (Figure 10a, from Schott et al., 2006) focused on the deep water transport of the DWBC and its variability. The array was finally recovered in 2005 and not re-deployed, the main reason being the difficulty to determine DWBC transports in the presence of a deep reaching North Atlantic Current (NAC). However, for the present objective we have a long time series of the DWBC covering almost a decade.

Regarding the mean currents at this location, we see increasing southward flow toward the bottom and underneath the $\sigma_{\theta}=27.80 \mathrm{kgm}^{-3}$ level (Figure 10). Mooring K104 is thereby located in the deep basin but close to the topographic slope of the Grand Banks. Here, the variance (Figure 10b) increases toward the bottom, while the mean flow is rather weak.

The spectrum of alongshore currents is significantly shifted toward lower frequencies compared for example to the DWBC in the Irminger Sea. In relation to the mainly barotropic flow farther north, we here see the near surface flow associated with the North Atlantic Current (NAC) being strong and in opposite direction to the DWBC underneath. The longer periods of the DWBC variability are likely caused by NAC meandering, and this makes 
transport estimates on longer time scales more difficult; and uncertainties (the number of degrees of freedom, NDF, are smaller) are larger than farther up north.

This topic has also been addressed in a recent paper of Peña-Molino et al. (2012) where the high frequency variability (19-50 day periods) in the deep flow along the US-coast (mooring line 'W') has been associated with topographic Rossby waves (TRW), while the longer term variability is caused by the meandering and eddy shedding of the Gulf Stream. Different from what is observed in the subpolar region is the existence of multiple frequency peaks, while in the observations shown here, the variance is mainly concentrated in a single peak.

At this point we like to summarize the main results from the observations obtained so far. All along the DWBC path, intra-seasonal variability dominates the deep flow. The longest time series at Angmagssalik and at the exit of the Labrador Sea exhibit the sharpest spectral energy peak with similar periods near $10 \mathrm{~d}$ time scales. The shortest time scales (near 5d) are observed directly in Denmark Strait, and the longest boundary current fluctuations are along Flemish Cap and the Grand Banks. In the following we will compare these findings to the large scale by using model data, and at the same time test for consistency between the model and observations.

\section{3) VIKING20 - high-resolution modeling of the subpolar North Atlantic}

For this study we use a very high-resolution model (VIKING20) that will be briefly described. The numerical ocean model is based on the NEMO code (version 3.1.1, Madec 2008) and belongs to the DRAKKAR framework (DRAKKAR Group, 2007). The global ocean-sea-ice configuration (LIM2, Fichefet and Morales Maqueda, 1997) and is discretized on a tripolar horizontal grid with a nominal resolution of $0.25^{\circ}$ (ORCA025) and $46 \mathrm{z}$-levels in the vertical.

The vertical layer thickness is $6 \mathrm{~m}$ near the ocean surface and increases with depths. A partialcell approach is used for the bottom cell (Barnier et al., 2006). Especially in the subpolar North Atlantic it has been demonstrated that this leads to an improved boundary current circulation (Käse et al., 2001). A regional grid refinement (AGRIF, Debreu et al., 2008) over the northern North Atlantic (from $\sim 30^{\circ} \mathrm{N}-85^{\circ} \mathrm{N}$ ) is embedded in the global configuration via a "two-way nesting" approach. The horizontal resolution in this high-resolution domain is nominal $0.05^{\circ}$ (corresponding to horizontal grid scales between $\sim 5 \mathrm{~km}$ and $\sim 1 \mathrm{~km}$ ). The "twoway nesting" approach allows an active interaction of signals between both grids, thus embeds the regional grid in the global circulation at all time scales. The turbulent vertical mixing is simulated with a 1.5-level turbulent kinetic energy scheme (Blanke and Delecluse, 1993). Viscosity is discretized for momentum by a bi-Laplacian, diffusion by an iso-neutral Laplacian scheme. The model does not simulate tides.

The model uses climatological temperature- and salinity fields (Levitus 1998) for initialisation. The simulation is based on a 30-year spin-up with the base model alone, then a hindcast simulation was integrated using the CORE2 (Large and Yeager, 2008; Griffies et al., 
2009) atmospheric forcing fields 6-hourly (wind speed, humidity, and atmospheric temperature), daily (short- and long-wave radiation), and monthly (rain and snow) resolutions, with interannual variability over the time range 1948-2007. To avoid a long-term model drift and taking uncertainties in the forcing fields into account, modelled sea-surface salinities (SSS) are weakly damped towards climatology with a piston velocity of $16 \mathrm{~mm} /$ day (corresponding to a time scale of eight years for $50 \mathrm{~m}$ surface layer), except for ice covered regions and the continental shelf around Greenland (Behrens et al., 2013).

As for the observational efforts we have chosen the 7 locations shown in Figure 1. Section orientation is perpendicular to the topography, although that is not so important for the present investigation. Here, we are interested mainly in the flow variance in main current direction, and for this we analyze the alongshore flow at individual grid point data. The model data for the long time scales are stored in 5-day averages, which is not sufficient for the short time scale investigation herein. Therefore, an additional model run over a two year period was performed for this investigation and stored as one-day averages.

The model environment used herein is shown in Figure 11, where we see a snapshot (5-day mean) of the current speed along the density surface $\sigma_{\theta}=27.85 \mathrm{kgm}^{-3}$, i.e. in the density range of the overflow water masses. This map reveals the characteristic features of the deep flow in the model domain. Downstream from Denmark Strait, a continuous current maximum is hugging the continental shelf break. This is associated with the path of the overflow plume from its source along the East and West Greenland coast. At the location of the Angmagssalik array the overflow plume covers most of the continental slope, and while the observations concentrate of the bottom layer only, the model shows an upward more barotropic extent of the flow. In this model snapshot the inner Labrador Sea shows regions of enhanced flow speed but is rather dominated by mesoscale activity. Along the Labrador shelf break we again see the band of strong currents, and the mean model-flow is quite similar to the observed one, even the bottom intensification is simulated by the model. The narrow DWBC exists until the flow enters the Orphan Knoll region where eddies dominate the flow. The DWBC is then re-established around Flemish Cap and the Grand Banks. In addition to the DWBC flow we see intense flow pattern in the central Labrador Sea and near the region of the Northwest Corner of the North Atlantic Current. What is also indicated in this instantaneous current field are the regions of low speed just offshore the DWBC and on both sides of the Labrador Sea; these are the recirculation cells reported by Lavender et al. (2000), Käse et al. (2001), and Fischer and Schott (2002). The Irminger Sea does not exhibit similar recirculation bands but instead a relatively intense eddy field offshore of the DWBC.

Generally, in areas where the topographic slope is strong, a narrow DWBC hugging the continental slope is visible in the western subpolar North Atlantic. In contrast, the basin centers, e.g., the inner Labrador Sea, show less organized flow pattern. In these and other areas with weak bottom slopes the flow appears to be dominated by mesoscale eddies. Observations by profiling floats (Fischer and Schott, 2003) indicate that there is a long residence time of water in the basin interior, which might influence the exchange between the convective areas and the NADW export routes. 


\section{4) Discussion of Results}

For each of the array locations we extracted high resolution (VIKING20) model data to be compared with respect to statistical parameters (variance spectra). For model validation the models have to produce the gross flow structures and their variability. Gross structures are for example transports, which need to be represented in magnitude and variability. Herein, we concentrated on the dominant variability of the DWBC in the subpolar North Atlantic. The observations are from discrete locations and the model will then be used to relate the individual flow structure to the large scale picture.

\subsection{Model Boundary Current variability related to the observations (Model validation)}

First we compare the model variability with the observations at the Labrador shelf break from the $53^{\circ} \mathrm{N}$ array (Figure 12).

The model spectra from $50 \mathrm{~m}$ above the bottom reveal variance maxima which are significantly lower than the corresponding deep records observed at the same location - the records from the DSOW core at $2700 \mathrm{~m}$ to $2800 \mathrm{~m}$. The high frequency peak is shifted toward lower frequencies (20-day periods rather than 10-day periods in the observations). Additionally, the model variability has a secondary, even higher maximum, at 50d-periodicity which is not seen in the observations. In this $50 \mathrm{~d}$ - band the observed variance decays to very low values - this may partly be caused by the much longer observations compared to the 2-years of model data. However, at the inshore side of the K9 location this 50d period has vanished almost completely, while offshore there is only the $50 \mathrm{~d}$ - peak.

When we follow the path of the DWBC and compare model and observational spectra of the near bottom flow (Figure 13), then we see at several places that the observed variance exceeds that of the model variance. This is strongest for the records in Denmark Strait, where the model variance at the 5-10d-peak is a factor of 5 smaller than the observed variance at a similar period. The rather short model series results in 3 variance peaks at $30 \mathrm{~d}, 8 \mathrm{~d}$ and $4-5 \mathrm{~d}$ periods.

If we look into the records of Angmagssalik (Figures 5b, and 13), this time in comparison with the model data, then the first thing to note is the complex structure of the topography (very steep shoreward of the moored array and more gentle in the region of the array - model topography is close to ETOPO 2 data set and this corresponds well to high resolution shipboard bathymetry). The mean flow along the topography is almost twice as large in the model as in the observations, and contrary to the observations the deep model flow (not shown) exhibits a strong seasonal cycle, which is not detected in the observations (this needs further attention in a separate investigation). While the total variances are similar, near $50 \mathrm{~cm}^{2}$ 
$\mathrm{s}^{-2}$, the frequency distribution is different. The model has strong intra-seasonal variability at very high frequencies (less than 10d) while the observations show the general $10 \mathrm{~d}$ peak. If we chose grid points farther offshore, where the slope is even gentler, then the peak frequency shifts toward the observed $10 \mathrm{~d}$ variance.

At Cape Farewell in the DWBC the high frequency variance is considerably smaller than farther upstream the DWBC, and here the observed variance is significantly higher than the modeled variance, and the same is true for $53^{\circ} \mathrm{N}$ in the Labrador Sea. Maximum variance at both locations occurs at similar frequencies, but these are not so well defined compared to Angmagssalik. The much broader spectral shape may be due to the fact that the time series are short, but it may also be caused by the gentler slope of the topography at this location. The situation at $53^{\circ} \mathrm{N}$ can be described by a lower variance level in the model simulation and somewhat longer periods.

At Flemish Cap, the shape of modeled and observed spectra is similar, and peaks occur around 50d with some variance at higher periods in the observations but not in the model. Along the DWBC this location is the only one where the variance peak is a little higher in the modeled flow. Farther south, at the tail of the Grand Banks the model shows less variance, but again at similar but longer (30-50d) periods.

Summarizing, the model reveals variance maxima at intra seasonal periods, but the model variance levels are generally smaller than the observed ones and the peak frequencies a rather different in some places although the topography appears to be represented properly. 4.2 Variability in the

\section{basin centers of the Labrador and Irminger Seas}

In terms of interpreting the larger scale variance distribution we also compare the boundary current regimes with the basin interior where we also have long term records in both, the Labrador and Irminger Seas. The Labrador Sea station (mooring K1, see Figure 1) is a continuation of the former Weather Ship "BRAVO" and successive Canadian moorings. It is also located on WOCE section AR7W, which is occupied by BIO researchers every spring. From 1996 onwards, a mooring has been installed to measure open ocean convection and the large scale heat content by Acoustic Tomography. The mooring has current meters (Aanderaa rotor current meters and ADCP's) as well as T/S sensors from near surface to $2000 \mathrm{~m}$ depth. This is of course too shallow for the overflow water mass layers, but as the flow was rather barotropic with even the spectral levels not very different between shallow and deep current records (Figure 14) we include this in our discussion about regional differences of intraseasonal current variability.

Intra-seasonal variance in the central Labrador Sea is comparable or even larger than that of the boundary current, but the frequency distribution is very different. Here, we have an energy maximum at 50d periods and there is almost no variance in the 5-10 day band. The mean flow thereby is small, and the variance ellipse has no principal axis, indicative of mesoscale eddies as the origin of the variance. This is similar for the corresponding model spectra (Figure 14), where lower frequencies around 50d also dominate the spectra. However, 
while the variance level in the observations are almost the same over the top $1500 \mathrm{~m}$, the model variance decays considerably with depth.

As a reference for the Irminger Sea basin we used observations from the Central Irminger Sea (CIS) mooring. CIS is equipped with ADCP (mainly upper $150 \mathrm{~m}$ ) and current meters $(1000 \mathrm{~m}$ and occasionally $2500 \mathrm{~m}$ ). The longest continuous record over 10 years at nominal $1000 \mathrm{~m}$ depth was used for analysis which show variance maxima at lower frequency compared to the adjacent boundary current (Figure 14, right). However, the energy level is only half that of the central Labrador Sea, and the periods are more in the 20 to 30 day range. The model spectra at CIS reveal a similar frequency distribution, but the variance level is considerably smaller than observed. In the basin center the model variance peaks near $50 \mathrm{~d}$ and at a level that is similar to that of the central Labrador Sea.

\subsection{Comparisons of observed and modeled spectral estimates across the Labrador Sea}

The WOCE AR7W-section runs from the Labrador shelf to West Greenland and passes through the position of mooring $\mathrm{K} 1$. We have spectral estimates from observations in the Boundary Current $\left(\right.$ at $53^{\circ} \mathrm{N}$ ) and in the basin center. For comparison we extracted the AR7W section from the VIKING20 model data, calculated the EKE distribution on that section (Figure 15a), and performed a spectral analysis for individual depth levels. For comparison we have done this for two depth levels, the surface and at 1000m depth (Figure 15), because mooring K1 has only records in the upper $2000 \mathrm{~m}$.

Similar to the observations we see a different behavior of intra-seasonal fluctuations - longer periods in the basin interior and shorter periods in the boundary currents at both sides of the basin, and more pronounced at the Greenland side. It is also very interesting, that on either side of the interior variability maximum there is a zone of very low energy. When comparing this with the circulation of the Labrador Sea, then these low energy bands coincide with the weak recirculation cells that were first observed by Lavender et al. $(2000,2005)$ and by Fischer and Schott (2002) in the trajectories of profiling floats.

In a related paper, Straneo et al. (2003) investigated the role of diffusion vs. advection on the spreading of LSW in adjacent basins. They estimated a rather long residence time of LSW in the central Labrador Sea (4.5 years) and with respect to the results shown here, the interior weakly stratified regime appeared separated from the boundary current regime. Evidence of interior separation is seen in individual float trajectories (Fischer and Schott, 2002) drifting slowly into the Labrador Sea within one of the recirculation cells connecting the Orphan Knoll area with the central Labrador Sea. There is additional evidence in the spectra of mooring K10 (Figure 7; the mooring at the transition between the DWBC and the recirculation) which showed much lower variance in all levels. The deepest record at the K10 location is still inside the deep DSOW current core and contains the highest variance level at that position, but the variance maximum occurs near the interior periodicity. Higher up in the 
water column the variance and the mean flow is much smaller and the mean current is in opposite direction to the DLC.

By using an intermediate resolution model, Käse et al. (2001) were able to reproduce these recirculation cells and argued that the flow is controlled by bottom topography. Local wind forcing and the baroclinic structure of the dense overflow plume play an important role. Due to improved representation of the bottom topography by partially filled cells (also used in VIKING20), circulation changes communicated by topographic waves are simulated more realistically.

Baroclinic structures of the boundary current at the exit of the Labrador Sea are confined to the shelf edge, where the Labrador Current is surface intensified and sheared down to a depth of several hundred meters (Fischer et al., 2004).

The shear-zone extends out to mooring $\mathrm{K} 8$, but further out at $\mathrm{K} 9$ there is only weak shear down to the overflow level. However, the deepest records again show strong shear in the near bottom records, and this is also true at K10 even farther away from the shelf break. Apparently, the intra-seasonal variability is confined to the sloping topography. Theoretical consideration (Olbers et al., 2012) tells us that the period of topographic waves in the presence of weak stratification is mainly determined by the slope of the topography - in a way that steep topography leads to high frequency waves. So, why then are the periods so similar at 8 to 12 day periodicity? All along the western subpolar NA the topographic slope is steep, with one exception, and that is at Cape Farewell and its underwater extension, the Eirik Ridge, where the slope is twofold, first steep and then much gentler - and although not significant, the records from the CF-Array exhibit longer periods (20 days) as well.

Another test for topographic Rossby Waves would be the principal orientation of the variance ellipses, which should be pointing in the direction of the DWBC flow. This has been shown farther downstream the DWBC in the Mid Atlantic Bight (Fratantoni and Pickart, 2003) and discussed for moored data at Line W (Pena-Molino et al., 2011) in which TRW are discussed to be responsible for bottom intensified variability at periods around 30d. For a comparable analysis we performed a principal axis de-convolution and found that the direction of the variance ellipse near the bottom is in the direction of the mean flow (within a few degrees). The $53^{\circ} \mathrm{N}$ array is well suited to discuss the structure of the variance orientation (Figure 16) in more detail. We already noted a frequency shift toward lower frequencies when we approach the deep sea basin (Figure 7 near bottom spectra). This is a strong indication that the $10-20$ day waves are trapped at the topography. Furthermore, we note that the near bottom variance (high pass filtered currents at 60d cut-off period) is larger along the topography than perpendicular to the isobaths for instruments on the slope. Offshore of the slope, the variance ellipses become more circular. For the layers above the near bottom flow intensification, e.g. at mid-depth (Figure 16b) the orientation of the variance ellipses is no longer in the direction of the topography, and we therefore plotted the ellipses for the whole water column in the center of the DWBC (mooring K9). Approximately 1000m above the bottom the ellipses are 15 
no longer oriented along the topography (Figure 16c) and the variances are somewhat smaller in this mid-depth layer and the main axis rotated from along the topography counterclockwise to almost perpendicular to the topography in the upper layers.

The same products have been generated for the model data, i.e., the daily model currents were high pass filtered at $60 \mathrm{~d}$ cut-off period and the near bottom current variance near the mooring line is shown in Figure 17. Variance ellipses were oriented almost perfect along the topography and the cross-component is very small compared to that along the principle axis. This is different from the observations, where the ratio of the two components is much smaller. Toward the deep basin the cross-variance increases and the overall variance becomes larger compared to that on the slope. Different to the observations is the vertical structure of the variance ellipses, which at mid-depth are still oriented along the topography showing similar structures to the near bottom model flow. Thus, the variance field is much more coherent in the model than in the observations.

The different structure of the variance ellipses can be summarized in a single number, the ellipticity (EP) of the variance ellipsoid $\mathrm{EP}=(1-\mathrm{b} / \mathrm{a})$, with $\mathrm{a}, \mathrm{b}$ the magnitude of the variance axes ( $a$ in the direction of maximum variance.) In the case of pure eddy motion, $a$ and $b$ are equal and EP becomes zero; in the case of all variance concentrated in one direction EP approaches unity.

The ellipticity, shown (Figure 18) for two different model configurations, exhibit strong maxima in the boundary current, that is clearly intensified toward the bottom where it approaches unity. Toward the basin center, the flow variability has no preferred direction and the small ellipticity indicates eddies as its origin. In the coarse resolution ORCA model the boundary currents are much wider, and especially the Deep Labrador Current extends unrealistically far into the basin. From just visual inspection the VIKING20 flow field resembles the real flow, and we have a bottom intensified DSOW core off the Labrador shelf break, which is not the case in lower resolution models.

Similarly, the observed flow field on both sides of the Labrador Sea reveals variability which is mainly directed in mean flow direction. When comparing the upper and intermediate (LSW) layers at the $53^{\circ} \mathrm{N}$ array, then $\mathrm{EP}$ is in the range 0.1 to 0.2 . The main variance axis (a) coincides with the mean flow direction. At depth, in the overflow layers the ellipticity is larger, between 0.3 and 0.5 . this is in contrast to the interior Labrador Sea, where at mooring $\mathrm{K} 1$ we find rather low EP $(\mathrm{O}(0.1))$, suggesting that mesoscale eddies dominate the variance field at this location.

Interestingly, the spectra along the sloping shelf have discrete maxima (usually 1 or 2 ) suggesting that these are TRW's generated by the instability of the boundary current, and whose frequency is determined by the slope of the topography (e.g., Stocker and Johnson, 1989). Increased stratification, as in summer situations, should increase the wave frequency, but this is not observed. Nevertheless this would be in agreement with the confined energetic 
zone over the slope, a low energy band adjacent to the topography, and an interior zone of low frequency variance.

\subsection{Seasonality of the intra seasonal boundary current variability?}

Early investigations (Fischer et al. 2004) of the mean flow structure in the Labrador Sea showed an annual cycle of the shallow Labrador Current extending out to the location of K9, but no seasonality in the LSW layer. There was a weak indication of seasonality in the deep current core, but this was insignificant. These results are consistent with the time series analysis from the sill of Denmark Strait, were the seasonality was found to be very small in both the transports and the hydrographic properties (Jochumsen et al., 2012). Here, we ask the question, is there any seasonality in the intensity of the intra-seasonal fluctuations. And indeed, there is a shallow maximum in the 10-15 d variance band at the time of the winter maximum of wind stress curl over the Labrador Sea. For this plot (Figure 19) 128d segments centered monthly are used to generate variance spectra which are then ensemble-averaged over the whole mooring duration. As an example: for the month March we used data from the period 64 days before March 15 until 64 days after March 15. For an individual month we had nine (the length of the time series at K9 is 9 years) such $128 \mathrm{~d}$ long segments which we average in spectral domain to improve the significance of an individual spectral estimate.

To our surprise we also see a deep seasonal cycle in the same period band, but with much lower variance (note the different scale in Figure 19). At depth, the maximum intra-seasonal variance is in fall to winter, i.e. the phase appears to be shifted. This could explain the small seasonal variance peak seen in Figure 3, but this is a rather weak signal only detected in the long time series at $\mathrm{K} 9$, and it is , but this could stimulate a future discussion about deep seasonal cycles in the subpolar North Atlantic.

\section{5) Summary and discussion}

We investigated the intra-seasonal variability of the DWBC in mooring data from the overflow source at Denmark Strait, along East Greenland, from the interior Labrador Sea to its exit, then around Flemish Cap toward the tip of the Grand Banks.

Long topographic waves are mostly independent of stratification, they are barotropic and the topographic slope determines their frequency. While strong slopes are observed around the Labrador Sea and off East Greenland, the array at Cape Farewell is located above a gentler descending shelf break. In fact, there is a steep part and a more moderate descent. This location has 10d variability, but it also shows some variance toward lower frequencies as one would expect from TRW's. For these TRW's, wave length of the order of 100 to $200 \mathrm{~km}$ are shorter or just comparable to the distance between arrays, and we tried to find indications of a coherent signal along the Labrador Sea shelf break (from Hamilton Bank to $53^{\circ} \mathrm{N}$ along the same isobath), but could not find any. This is different for thermohaline anomalies which on 
much longer time scales were tracked from the Labrador Sea into the open North Atlantic (Stramma et al., 2004).

There are four main aspects of this investigation, first there is the variability which is interesting by itself, and then there is a first validation of a new high resolution model regarding the representation of intra-seasonal variability near the continental margin. The model might be used to relate discrete and sparse observations to the large scale hydrographic and circulation pattern as has been shown here for the Labrador Sea. Finally, the intraseasonal energy peak controls how accurate estimates of long term (seasonal to decadal) fluxes and transports can be. In detail, these are the main results:

- Topographic waves near $10 \mathrm{~d}$ periods dominate the variance of the Boundary Current in the Irminger and Labrador Sea's. Shorter periods $(\sim 5 \mathrm{~d})$ were only found at the sill of Denmark Strait.

- At Flemish Cap and farther south there is also strong variance at somewhat lower frequencies $(30-60 \mathrm{~d}$ periods).

- The central Labrador Sea (from Mooring K1 in its center) exhibits 50d periods as the most energetic with almost no variance at 10 days;

- Simulations with a high resolution model are used to relate local observations to the larger scale environment.

- The two regimes, DLC and interior Labrador Sea are separated by a band of weak mean flow into the Labrador Sea that also has very week eddy energy.

- Topographic waves are trapped at the steep slopes around the subpolar NA and in the presence of low stratification the bottom slope determines the frequency of the waves.

Comparison of the high frequency variability represented in a high resolution model with moored observations reveals remarkable differences at the intra-seasonal time scales. Having discussed the above points, we here will concentrate on the third point, namely the question how accurate are our estimates of deep water transports across $53^{\circ} \mathrm{N}$ for example, and what will be the influence of the intra-seasonal variance. Table 2 summarizes the statistics of the flow in the deep water range below $\sigma_{\theta}=27.80 \mathrm{kgm}^{-3}$. We compare the total alongshore variance to the variance contribution for periods less than $60 \mathrm{~d}$ and find that in almost any case the intra-seasonal variance accounts for 70 to $90 \%$ of the total variance. For the error estimation of the mean flow (e.g. say for annual means) we estimate the integral time scale of the deep flow at several of the locations by two methods: first, through integration of the auto - correlation functions of the respective time series, and second by estimating the (degrees of freedom) DOF's from the first zero crossing of the autocorrelation function (usually better defined) multiplied by two -- assuming data are statistically independent after half a wavelength. Both estimates are somewhat more conservative than for example the estimate of Daniault et al., 2010 of around $5 \mathrm{~d}$ for the Cape Farewell data set. The error of annual mean flow is then estimated by: $\operatorname{stdev}(\mathrm{U}) / \mathrm{sqrt}(\mathrm{DOF})$ and is listed in Table 2. The largest errors are expected in the Denmark Strait records, where the largest observed variance is not 
compensated by the somewhat shorter integral time scale (more DOF). On the other hand the frequency shift observed south of Flemish Cap leads to smaller DOF (larger integral time scale) and thereby to larger errors.

Another error estimation is carried out by successively applying a low pass filter to the longest time series with increasing cutoff periods (5d to 100d). From these filtered time series we calculated the residual variance over the whole duration $(\sim 5 \mathrm{y})$. With increasing cut-off period the residual variance decreases as expected until a $20 \mathrm{~d}$ cut-off period when most of the intra-seasonal variance is filtered out. Thereafter, the residual variance decreases much slower and approaches small values $\left(<10 \mathrm{~cm}^{2} \mathrm{~s}^{-2}\right)$ after a cut-off of $60 \mathrm{~d}$. These values might be used to determining the DOF. Thus, a one year long time series filtered that way has just 5-6 DOF, and the corresponding error of the mean is determined by dividing the residual standard deviation divided by the square root of DOF - at K9 the low pass filtered (60 day cut-off) time series reveals a residual variance of $7 \mathrm{~cm}^{2} \mathrm{~s}^{-2}$, and thus an error of the mean of an individual record would be $1 \mathrm{~cm} \mathrm{~s}^{-1}$. For an individual LADCP section which takes about two days to perform, the inherent variance would be of the order of $25 \mathrm{~cm}^{2} \mathrm{~s}^{-2}$ or a standard deviation of $5 \mathrm{cms}^{-1}$. While one would need 5 times $60 \mathrm{~d}$ in the moored and filtered record, one has significantly more ship sections to perform in order to get an uncertainty less than or equal to $1 \mathrm{~cm} \mathrm{~s}^{-1}$.

Although we discussed the impact of the intra-seasonal variance mainly for the $53^{\circ} \mathrm{N}$ array, the corresponding values for the other arrays are determined as well, and are summarized in Table 2. This result illustrates that in a highly resolved time series of say annual duration the intra-seasonal part is almost completely removed through averaging, with a tendency toward larger errors in the more southerly parts of the DWBC and in the basin interior.

Acknowledgements: The research leading to these results has received funding from the German Ministry of Research and Education (RACE-program, $53^{\circ} \mathrm{N}$ and at Flemish Cap $47^{\circ} \mathrm{N}$ arrays), and the European Union's Seventh Framework Programme (FP7/2007-2013) under grant agreements no. 212643 (THOR) and no. 308299 (NACLIM). The Cape Farewell array was funded by the Natural Environment Research Council under Grant NER/T/S/2002/00453. Model integrations were performed at the North-German Supercomputing Alliance.

\section{Literature}


Bacon, S.: RRS Discovery Cruise 298, 23 Aug - 25 Sep 2005, (2006a). Cape Farewell and Eirik Ridge (CFER-1). National Oceanography Centre, Southampton, Cruise Report No. 10, $113 \mathrm{pp}$.

Bacon, S.: RRS Discovery Cruise 309-310, 18 Aug - 5 Sep 2006, (2006b). Cape Farewell and Eirik Ridge (CFER-2). National Oceanography Centre, Southampton, Cruise Report No. 11, 113 pp.

Bacon, S.: RRS Discovery Cruise 332, 20 Aug - 25 Sep 2008, (2010). Arctic Gateway (WOCE AR7). National Oceanography Centre, Southampton, Cruise Report, No. 53, 129 pp.

Bacon, S. and P. M. Saunders. The Deep Western Boundary Current at Cape Farewell: Results from a Moored Current Meter Array. (2010). J. Phys. Oceanogr. 40, 815-829.

Barnier B, Madec G, Penduff T, Molines J, Treguier A, Sommer J L, Beckmann A, Biastoch A, Böning C, Dengg J, Derval C, Durand E, Gulev S, Remy E, Talandier C, Theetten S, Maltrud M, McClean J, and Cuevas B D, (2006); Impact of partial steps and momentum advection schemes in a global ocean circulation model at eddy permitting resolution. Ocean Dyn. 56, 543-567.

Behrens, E., A. Biastoch, and C.W. Böning, (2013). Spurious AMOC trends in global ocean sea-ice models related to subarctic freshwater forcing. Ocean Modelling, Vol. 69, p39-49 doi:10.1016/j.ocemod.2013.05.004

Blanke, B., and P. Delecluse, (1993). Variability of the tropical Atlantic Ocean simulated by a general circulation model with two different mixed-layer physics. J. Phys. Oceanogr., 23, 1363-1388, 1993.

Bower A.S., M. Susan Lozier, Stefan F. Gary, and Claus W. Böning, (2009). Interior pathways of the North Atlantic meridional overturning circulation. Nature 243-247. doi:10.1038/ nature 07979

Böning, C. W., Scheinert, M., Dengg, J., Biastoch, A. und Funk, A. (2006) Decadal variability of subpolar gyre transport and its reveberation in the North Atlantic overturning. Geophysical Research Letters, 33 . DOI 10.1029/2006GL026906.

Daniault, N., P. Lherminier, and H.Mercier, 2011: Circulation and Transport at the Southeast Tip of Greenland. J. Phys. Oceanogr., 41, 437-457. doi: http://dx.doi.org/10.1175/2010JPO4428.1

Debreu L, Vouland C and Blayo E, (2008). AGRIF: Adaptive grid refinement in Fortran Computer \& Geosciences 34, 8-13

Dengler, M., J. Fischer, F. A. Schott, and R. Zantopp: The Deep Labrador Current and its variability in 1996-2005, (2006). Geophys. Res. Letters, 33, L21S06, doi:10.1029/ 2006GL026702 
Dickson, B., S. Dye, S. Jónsson, A. Köhl, A. Macrander, M. Marnela, J. Meincke, S. Olsson, B.

Origind and Forcing, Verlag: Springer Berlin Heidelberg, Dickson, R., J. Meincke, and P. Rhines, Eds. Pp 443 - 474.

DRAKKAR Group 2007 Eddy-permitting ocean circulation hindcasts of past decades CLIVAR Exchanges No. 42 (Vol. 12, No. 3) International CLIVAR Project Office, Southampton, UK, 810

Eden, Carsten, Claus Böning, 2002: Sources of Eddy Kinetic Energy in the Labrador Sea. $J$. Phys. Oceanogr., 32, 3346-3363. doi: http://dx.doi.org/10.1175/1520-0485(2002)032<3346:SOEKEI>2.0.CO;2

Fichefet, T., and M. A. Morales Maqueda, Sensitivity of a global sea ice model to the treatment of ice thermodynamics and dynamics, J. Geophys. Res., 102(C6), 12609-12, 1997.

Fischer, J., and F. A. Schott: Labrador Sea Water tracked by profiling floats - from the boundary current into the open North Atlantic . J. . Phys. Oceanogr. 32 (2002), S. 573-584

Fischer, J., F.A. Schott, and M. Dengler: Boundary circulation at the exit of the Labrador Sea. J. Phys. Oceanogr. (2004), Vol. 34 (7), 1548-1570

Fischer, J., M. Visbeck, R. Zantopp, and N. Nunes, Interannual to Decadal Variability of Outflow from the Labrador Sea, Geophys. Res. Lett., (2010) doi:10.1029/2010GL045321.

Fratantoni, P. S., and R. S. Pickart (2003), Variability of the shelf break jet in the Middle Atlantic Bight: Internally or externally forced? J. Geophys. Res., 108, 3166, doi:10.1029/2002JC001326, C5.

Griffies, S.M. and coauthors, (2009), Coordinated Ocean-ice Reference Experiments (COREs). Ocean Modelling, Volume 26, Issues 1-2, 2009, Pages 1-46. http://dx.doi.org/10.1016 /j.ocemod.2008.08.007.

Holliday, N. P., S. Bacon, J. Allen, E. L. McDonagh, 2009: Circulation and Transport in the Western Boundary Currents at Cape Farewell, Greenland. J. Phys. Oceanogr., 39, 1854-1870. doi: http://dx.doi.org/10.1175/2009JPO4160.1

Jochumsen, K., D. Quadfasel, H. Valdimarsson and S. Jonsson (2012): Variability of the Denmark Strait Overflow: moored time series from 1996 - 2011, J. Geophys. Res., doi:10.1029/2012JC008244.

Käse, R.H., A. Biastoch, and D.B. Stammer (2001), On the Mid-Depth Circulation in the Labrador and Irminger Seas. Geophys. Res. Lett. Vol. 28, No. 18, pp. 3422-3436.

Large Wand Yeager S (2008), The global climatology of an interannually varying air-sea flux data set Climate Dynamics 33 341-364. 
Lavender, K. L., R. E. Davis \& W. B. Owens, (2000), Mid-depth recirculation observed in the interior Labrador and Irminger seas by direct velocity measurements, Nature 407, 66-69, doi:10.1038/35024048.

Lavender, K. L., W. B. Owens, and R. E. Davis, (2005), The mid-depth circulation of the subpolar North Atlantic Ocean as measured by subsurface floats. DSR-I, Vol. 52, 767-785. http://dx.doi.org/10.1016/j.dsr.2004.12.007.

Levitus S., and coauthors. (1998). Introduction. Vol. 1, World Ocean Database NOAA Atlas NESDIS 18, NOAA/NESDIS, U.S. Dept. of Commerce, Washington, D.C.

Macrander, A., U. Send, H. Valdimarsson, S. Jónsson, and R. H. Käse (2005), Interannual changes in the overflow from the Nordic Seas into the Atlantic Ocean through Denmark Strait, Geophys. Res. Lett., 32, L06606, doi:10.1029/2004GL021463.

Macrander, A., Käse, R.H., Send, U., Valdimarsson, H., Jónsson, S., (2007). Spatial and temporal structure of the Denmark Strait Overflow revealed by acoustic observations. Ocean Dyn. 57 (April), 75-89.

Madec G., (2008), NEMO ocean engine, Technical Report and Note du Pole de mod'elisation, Institut Pierre-Simon Laplace (IPSL) 27 ISSN No 1288-1619

Marshall, J., and F. Schott (1999), Open-ocean convection: Observations, theory, and models, Rev. Geophys., 37(1), 1-64, doi:10.1029/98RG02739.

Peña-Molino, B., T. M. Joyce, and J. M. Toole (2012), Variability in the Deep Western Boundary Current: Local versus remote forcing, J. Geophys. Res., 117, C12022, doi:10.1029/2012JC008369.

Pickart, R. S., and D. R. Watts, 1990. Deep Western Boundary Current variability at Cape Hatteras. Journal of Marine Research, 48, 765-791.

Olbers, D., J. Willebrand, and C. Eden (2012); Ocean Dynamics, Verlag: Springer Berlin Heidelberg, doi: 10.1007/978-3-642-23450-7, pp. 704

Rhein, M., D. Kieke, S. Hüttl-Kabus, A. Ströh, C. Mertens, R. Meissner, B. Klein, C. W. Böning and I. Yashayaev, (2011). Deep-water formation, the subpolar gyre, and the meridional overturning circulation in the subpolar North Atlantic. Deep-Sea Res. II, 58(17-18), 1819-1832.

Schott, F., L. Stramma , R. Zantopp, M. Dengler, J. Fischer, and M. Wibaux: (2004). Circulation and Deep Water export at the western exit of the subpolar North Atlantic. J. Phys. Oceanogr. 34, Vol. 34 (4), S. 817-843 
Schott, F., J. Fischer, M. Dengler, and R. Zantopp: (2006), Variability of the Deep Western Boundary Current east of the Grand Banks. Geophys. Res. Letters 33, L21S07, doi: 10.1029/2006GL026563

Smith, Peter C., 1976: Baroclinic Instability in the Denmark Strait Overflow. J. Phys. Oceanogr., 6, 355-371.

Stramma, L., Kieke, D., Rhein, M., Schott, F., Yashayev, I. und Koltermann, K. P. (2004) Deep water changes at the western boundary of the subpolar North Atlantic during 1996 to 2001 Deep-Sea Research Part I-Oceanographic Research Papers, 51 . pp. 1033-1056.

Straneo, F., R. S. Pickart, K. Lavender, (2003), Spreading of Labrador sea water: an advectivediffusive study based on Lagrangian data. Deep-Sea Research I 50, 701-719, doi:10.1016/S0967-0637(03)00057-8

Stocker, T. F. and E.R. Johnson: (1989). Topographic Waves in Open Domains. Part 2. Bay modes and resonances, J. Fluid Mech. Vol. 200, pp. 77-93

Thompson, R., and J. R. Luyten, 1976: Evidence for bottom-trapped topographic Rossby waves from single moorings. Deep-Sea Res., 23, 629-635.

Welch, P.D, (1967); The Use of Fast Fourier Transform for the Estimation of Power Spectra: A Method Based on Time Averaging Over Short, Modified Periodograms, IEEE Trans. Audio Electroacoustics, Vol. AU-15, pp.70-73.

Xu, X., H.E. Hurlburt, W.J. Schmitz Jr., R. Zantopp, J. Fischer, and J.J. Hogan, (2013). On the currents and transports connected with the Atlantic meridional overturning circulation in the subpolar North Atlantic. J. Geophys. Res., 118, 502-516. doi: 10.1002/jgrc.20065 


\section{Figure Captions}

Figure 1. The western subpolar North Atlantic and the location of current meter arrays along the path of the Deep Western Boundary Current (DWBC); from the sill at Denmark Strait to the transition into the subtropics at the tail of the Grand Banks. At each location near bottom variance ellipses (red) are included (grey ellipsoid is for scaling only - units in $\mathrm{cm}^{2} \mathrm{~s}^{-2}$ ). Also included are variance ellipses from the central Labrador and Irminger Seas. Green line is the former WOCE line AR7W which is occupied annually by Canadian researchers.

Figure 2: Top to bottom time series of alongshore currents at the central mooring K9 of the $53^{\circ} \mathrm{N}$-Array. Thin gray lines are from detided time series and dots are annual mean currents.

Figure 3: The raw spectra (variance conserving) of two current meter records that are several years long (see Figure 2), from mooring K9 in the center of the deep boundary current at the exit of the Labrador Sea. Ensemble averaged spectra from 128 day long subsamples as solid lines. Note the narrower spectral peak for the deep instrument. This procedure has been applied to all the records - namely de-tided by $40 \mathrm{~h}$ low-pass filtering, subsampled at $1 / 2 \mathrm{~d}$ resolution and overlapping (by 50\%) data subsets used for spectral analysis, and then ensemble averaged spectra are determined (red curve).

Figure 4: Overflow in Denmark Strait (a), currents in along-channel direction as a snapshot obtained from shipboard ADCP - blue is the Overflow; the heavy black line shows the isopycnal $\sigma_{\theta}=27.8 \mathrm{kgm}^{-3}$. Spectra of the Overflow (b) in the deep current core at Denmark Strait. Data are from moored ADCPs at the depth cell of maximum flow close to the sill depth. For deployment times see figure legend.

Figure 5: a) Snapshot of cross-section velocity from lowered ADCP data, as measured in July 2010 during cruise Meteor M82-1. Negative velocities are toward the southwest (blue), while positive velocities are northeastward (red). Two isopycnals are included in black: $\sigma_{\theta}=27.8$ $\mathrm{kgm}^{-3}$ as the upper boundary of the overflow components, and $\sigma_{\theta}=27.85 \mathrm{kgm}^{-3}$ as the upper Denmark Strait Overflow plume. The $\mathrm{x}$-axis gives the distance starting on the Greenland shelf. The recent Angmagssalik array is illustrated in yellow.

b) Spectra from the Angmagssalik array. Only near bottom records are shown; the depth above bottom is given in the figure legend (B-XXX). Left: Spectra from UK1 at $1980 \mathrm{~m}$ water depth, and a record length of 4 years. The record to the right (UK2 at $2350 \mathrm{~m}$ ) is very long (almost 7 years) and it shows a very narrow spectral peak at 8-12 day periods.

Figure 6: The Cape Farewell array. a) Mean velocity cross-array flow $(\mathrm{cm} / \mathrm{s})$ and mean depth of the $3^{\circ} \mathrm{C}$ isotherm; b) Spectra from the deepest instruments at moorings $\mathrm{B}$ and $\mathrm{H}$ in the core of the DWBC and below the $3^{\circ} \mathrm{C}$ isotherm which in this case represent the upper limit of the overflow waters. Instrumental depth of $\mathrm{H} 1$ and $\mathrm{H} 2$ are $1900 \mathrm{~m}$ and $2370 \mathrm{~m}$; B1 and B2 are $1980 \mathrm{~m}$ and $2450 \mathrm{~m}$, respectively. 
Figure 7: The current meter array at $53^{\circ} \mathrm{N}$ (top) at the exit of the Labrador Sea, and in its current configuration; in the background the mean boundary current from all available LADCP section (1997 to 2010) data. Alongshore currents were de-tided before calculating variance-conserving spectra shown in the 4 panels below. Spectra of the three core moorings (K8, K9 and K10) of the $53^{\circ} \mathrm{N}$ array all show the spectral peak at periods of 10-12 $\mathrm{d}$ through all depth levels. Near-shore at K8 the highest variance is near the surface layer. In the center of the DWBC (mooring K9) the DSOW core has highest variance and similarly at K10, but at strongly reduced amplitudes. The lower right graph shows the variance-conserving spectra of the near bottom flow at $53^{\circ} \mathrm{N}$ with maximum variance in the DSOW core at mooring $\mathrm{K} 9$ in the center of the array.

Figure 8: Distribution of instruments in the Flemish Cap mooring array. Mooring B22 is in the center, and B23 is located at the easternmost location, the moorings consist of several versions of acoustic current meters. The meridional velocity (blue: southward, red: northward) from lowered ADCP as observed in summer 2008 is used as a background. The black lines denote isopycnals used as deep water mass boundaries (left). Velocity spectra (right) of the three deep records in moorings B22 and B23 below the density surface $\sigma_{\theta}>$ $27.80 \mathrm{kgm}^{-3}$. The time series are up to 3 years long.

Figure 9: Currents at Flemish Cap from the mooring deployed 1998-1999 as a vector diagram (left) with currents rotated to $60^{\circ}$ true, such that flow along the topography is downward; currents are offset by $50 \mathrm{~cm} / \mathrm{s}$. Spectra of the time series (right).

Figure 10: a) Mean ship section of ADCP/LADCP currents parallel to the topography of the Grand Banks (after Schott et al. 2006), composed from four cruises in summers of 1999, 2001, 2002 and 2005. DWBC flows southward along the boundary, NAC flows northward offshore. Transports are given in density layers corresponding to the different NADW water masses.

b) Spectra from the Grand Banks mooring K104. Note, the variance increases toward the bottom, and maximum energy is found around the period of 30 days.

Figure 11: Model snapshot of the current speed along $\sigma_{\theta}=27.85 \mathrm{kgm}^{-3}$ representing the upper limit of the DSOW layer. For model / observation comparisons the location of the investigated variability are indicated as black lines.

Figure 12: Model-(left) and observed (right) spectra of the alongshore flow at $53^{\circ} \mathrm{N}$ at the locations of moorings K8, K9, and K10. For illustration the main frequencies (periods of 3d, 10d and 30d) are marked by dashed vertical lines. Data are from the near bottom instruments and corresponding grid cells of the model - variance scaling is different as observed variance is significantly larger. 
Figure 13: Spectral comparison of intra-seasonal variance. Observed spectra in blue, modeled

Figure 15: a) EKE distribution along the AR7W section from the 2-year long run of VIKING20; indicated is the position of mooring K1. b) Model spectral variance in $1000 \mathrm{~m}$ depth and at the surface, and c) variance in 1000m depth along WOCE section AR7W (for location see Figure 1. Spectral Amplitude is shown by color and is plotted for individual frequency (period) bands; note the different variance scale.

Figure 16: Variance ellipses at the $53^{\circ} \mathrm{N}$ array; (a) intra-seasonal variance ellipses measured close to the bottom (units are $\mathrm{cm}^{2} \mathrm{~s}^{-2}$ ); (b) the same, but for the $1500 \mathrm{~m}$ level (LSW layer); and (c) vertical structure of variance ellipses at mooring K9 in the center of the array. Bottom topography is from the 2' ETOPO data set and smoothed over a 10nm length scale; in Fig. $16 \mathrm{c}$, the orientation of isobaths at K9 is indicated by dashed lines. All data were high pass filtered at $60 \mathrm{~d}$ cut-off periods.

Figure 17: Variance ellipses as in Figure 17, but for model data near the $53^{\circ} \mathrm{N}$ mooring locations.

Figure 18: Ellipticity of the flow at the AR7W section across the Labrador Sea and between the shelf break of Labrador (left) to that of Greenland. Top graph is from a run of a model that has $14^{\circ}$ resolution and the lower graph is from the VIKING20 model.

Figure 19: Seasonal distribution of intra-seasonal variance. Spectral band (periods in days) is plotted versus time (month) of year. Data are from K9 near the surface (left) and near the bottom in the DSOW layer (right). Color bar is different from 0 to $30 \mathrm{~cm}^{2} \mathrm{~s}^{-2}$ and from 0 to 10 $\mathrm{cm}^{2} \mathrm{~s}^{-2}$. 
Table 1: Summary of Meta data of moored Arrays

\begin{tabular}{|l|l|l|l|l|}
\hline Array & location & PI & Institution & Period \\
\hline DSOW Array & Denmark Strait & $\begin{array}{l}\text { Quadfasel, Send, } \\
\text { Jochumsen, } \\
\text { Valdimarsson, } \\
\text { Jónsson }\end{array}$ & ZMAW/MRI/GEOMAR & $\begin{array}{l}1996-2012 \\
\text { (ongoing) }\end{array}$ \\
\hline $\begin{array}{l}\text { Angmagssalik } \\
\text { Array }\end{array}$ & $\begin{array}{l}\text { East Greenland } \\
\text { Slope }\end{array}$ & Dye, Quadfasel & CEFAS/ZMAW & $\begin{array}{l}1986-2012 \\
\text { (ongoing) }\end{array}$ \\
\hline Cape Farewell & $\begin{array}{l}\text { Tip of } \\
\text { Greenland }\end{array}$ & Bacon, Holliday & NOCS & $2005-2008$ \\
\hline $53^{\circ} \mathrm{N}$ & $\begin{array}{l}\text { Labrador Sea } \\
\text { Exit }\end{array}$ & $\begin{array}{l}\text { Fischer, Visbeck, } \\
\text { Karstensen, Zantopp }\end{array}$ & GEOMAR & $\begin{array}{l}1997-2012 \\
\text { (ongoing) }\end{array}$ \\
\hline FC-NA, $47^{\circ} \mathrm{N}$ & Flemish Cap & Rhein, Mertens & University of Bremen & $\begin{array}{l}2009-2012 \\
\text { ongoing }\end{array}$ \\
\hline Grand Banks Array & $\begin{array}{l}\text { Tail of Grand } \\
\text { Banks }\end{array}$ & $\begin{array}{l}\text { Schott, Fischer, } \\
\text { Zantopp }\end{array}$ & GEOMAR & $1999-2005$ \\
\hline
\end{tabular}

Table2: Near bottom current statistics for selected locations of the DWBC

\begin{tabular}{|c|c|c|c|c|c|c|c|c|}
\hline Location & $\begin{array}{l}\text { total } \\
\text { variance } \\
\mathrm{cm}^{2} \mathrm{~s}^{-2}\end{array}$ & $\begin{array}{l}\text { Hf-variance } \\
(<60 \mathrm{~d}) \\
\mathrm{cm}^{2} \mathrm{~s}^{-2}\end{array}$ & $\begin{array}{l}\text { Variance } \\
\text { ratio }\end{array}$ & $\begin{array}{l}\text { * Integral } \\
\text { Time Scale } \\
\text { days }\end{array}$ & DOF & $\begin{array}{l}\text { Error } \\
\mathrm{cm} \mathrm{s}^{-1}\end{array}$ & Slope $* *$ & $\begin{array}{l}\text { Ellipti } \\
\text { city }\end{array}$ \\
\hline Denmark Strait & 313.8 & 305.3 & 0.97 & 8 & 45 & 2.6 & --- & 0.47 \\
\hline Angmagssalik & 87.5 & 78.6 & 0.90 & 10 & 36 & 1.6 & $13 * 10^{-3}$ & 0.31 \\
\hline Cape Farewell & 38.1 & 32.3 & 0.85 & 12 & 30 & 1.1 & (60) $9 * 10^{-3}$ & 0.30 \\
\hline Central Lab. Sea & 119.8 & 50.5 & 0.42 & 60 & 6 & 4.5 & $-\overline{---}$ & 0.14 \\
\hline $53^{\circ} \mathrm{N}$ & 23.6 & 17.5 & 0.75 & 15 & 24 & 1.0 & $15^{*} 10^{-3}$ & 0.50 \\
\hline Flemish Cap & 35.2 & 28.7 & 0.82 & 22 & 16 & 1.5 & $40 * 10^{-3}$ & 0.30 \\
\hline Grand Banks & 60.2 & 46.8 & 0.78 & 22 & 16 & 1.9 & $9 * 10^{-3}$ & 0.34 \\
\hline
\end{tabular}

Integral Timescale $=$ first zero crossing of autocorrelation function at lag Tau/4 * 2

DOF for annual mean: $365 \mathrm{~d}$ divided by integral time scale

** Slope at location where $\sigma_{\theta}=27.80 \mathrm{kgm}^{-3}$ or the $3^{\circ} \mathrm{C}$ isotherm intersects the topography toward abyssal plane (reads as $\mathrm{m} / \mathrm{km}$ ) 


\section{Figures}

\section{Figure 1}

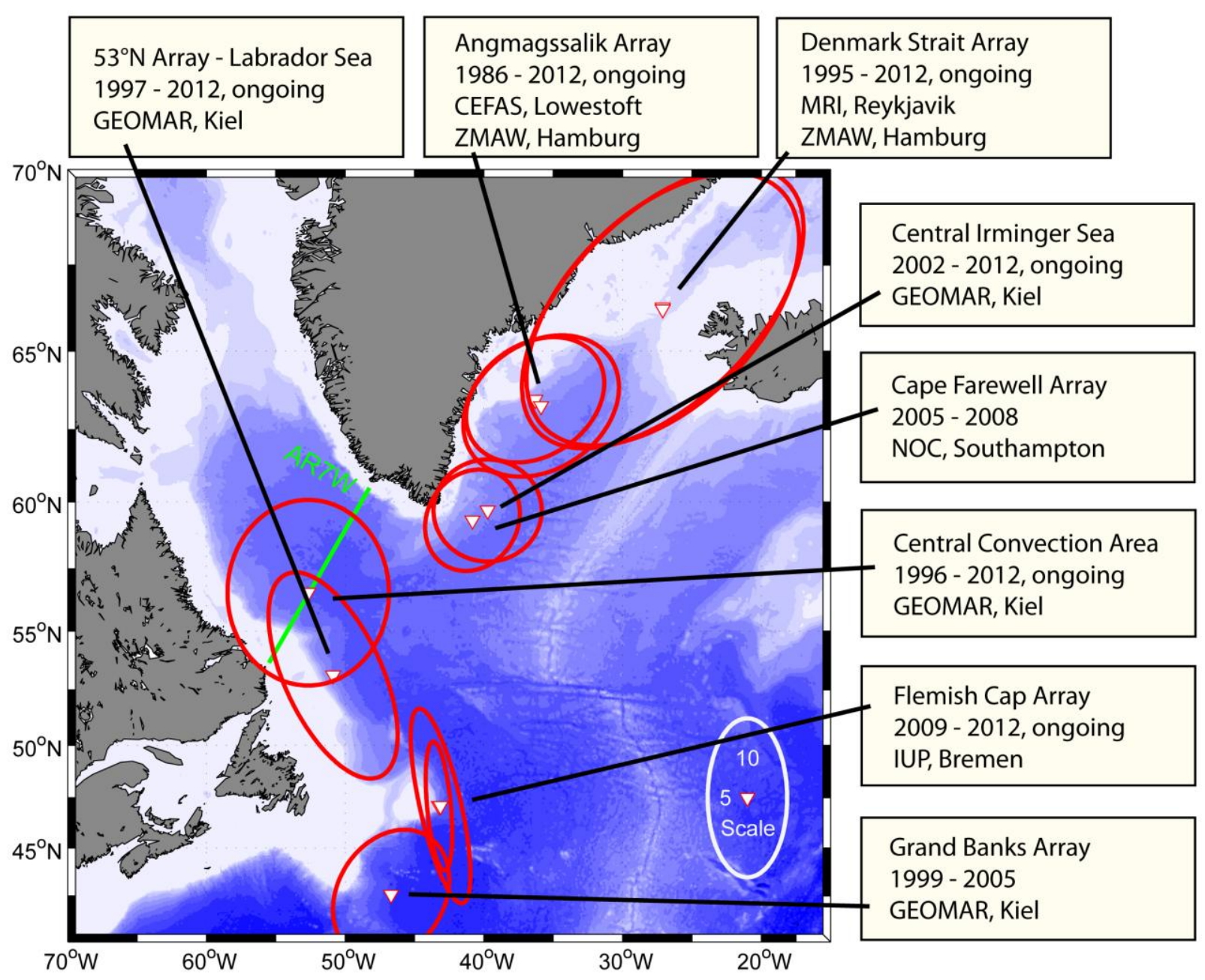

Figure 1. The western subpolar North Atlantic and the location of current meter arrays along the path of the Deep Western Boundary Current (DWBC); from the sill at Denmark Strait to the transition into the subtropics at the tail of the Grand Banks. At each location near bottom variance ellipses (red) are included (grey ellipsoid is for scaling only-units in $\mathrm{cm}^{2} \mathrm{~s}^{-2}$ ). Also included are variance ellipses from the central Labrador and Irminger Seas. Green line is the former WOCE line AR7W which is occupied annually by Canadian researchers. 


\section{Figure 2}

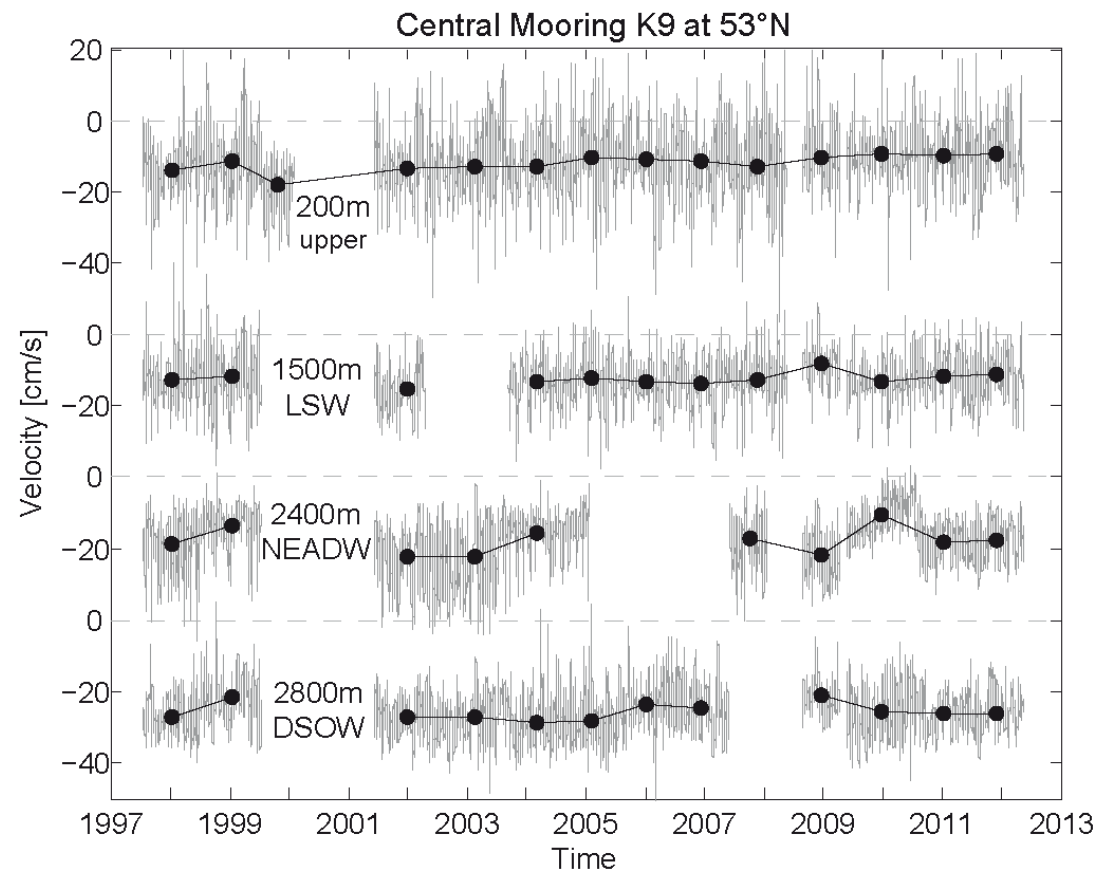

Figure 2: Top to bottom time series of alongshore currents at the central mooring K9 of the $53^{\circ} \mathrm{N}$ array. Thin gray lines are from de-tided time series and dots are annual mean currents. 


\section{Figure 3}
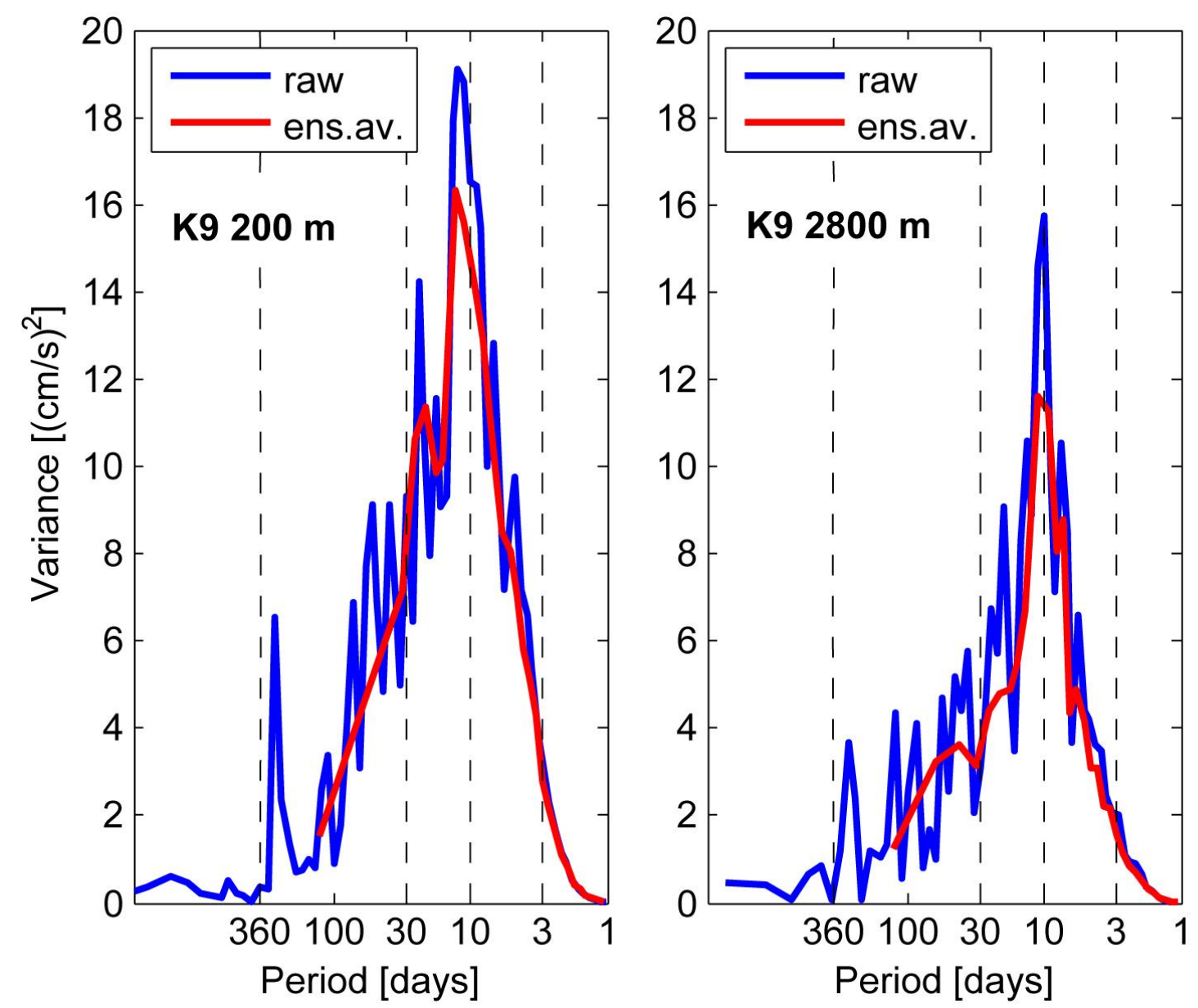

Figure 3: The raw spectra (variance conserving) of two current meter records that are several years long (see Figure 2), from mooring $K 9$ in the center of the deep boundary current at the exit of the Labrador Sea. Ensemble averaged spectra from 128 day long subsamples as red lines. Note the narrower spectral peak for the deep instrument. This procedure has been applied to all the records - namely de-tided by $40 \mathrm{hlow}$-pass filtering, subsampled at 1/2d resolution and overlapping (by 50\%) data subsets used for spectral analysis, and then ensemble averaged spectra are determined (red curve). 


\section{$\underline{\text { Figure } 4}$}
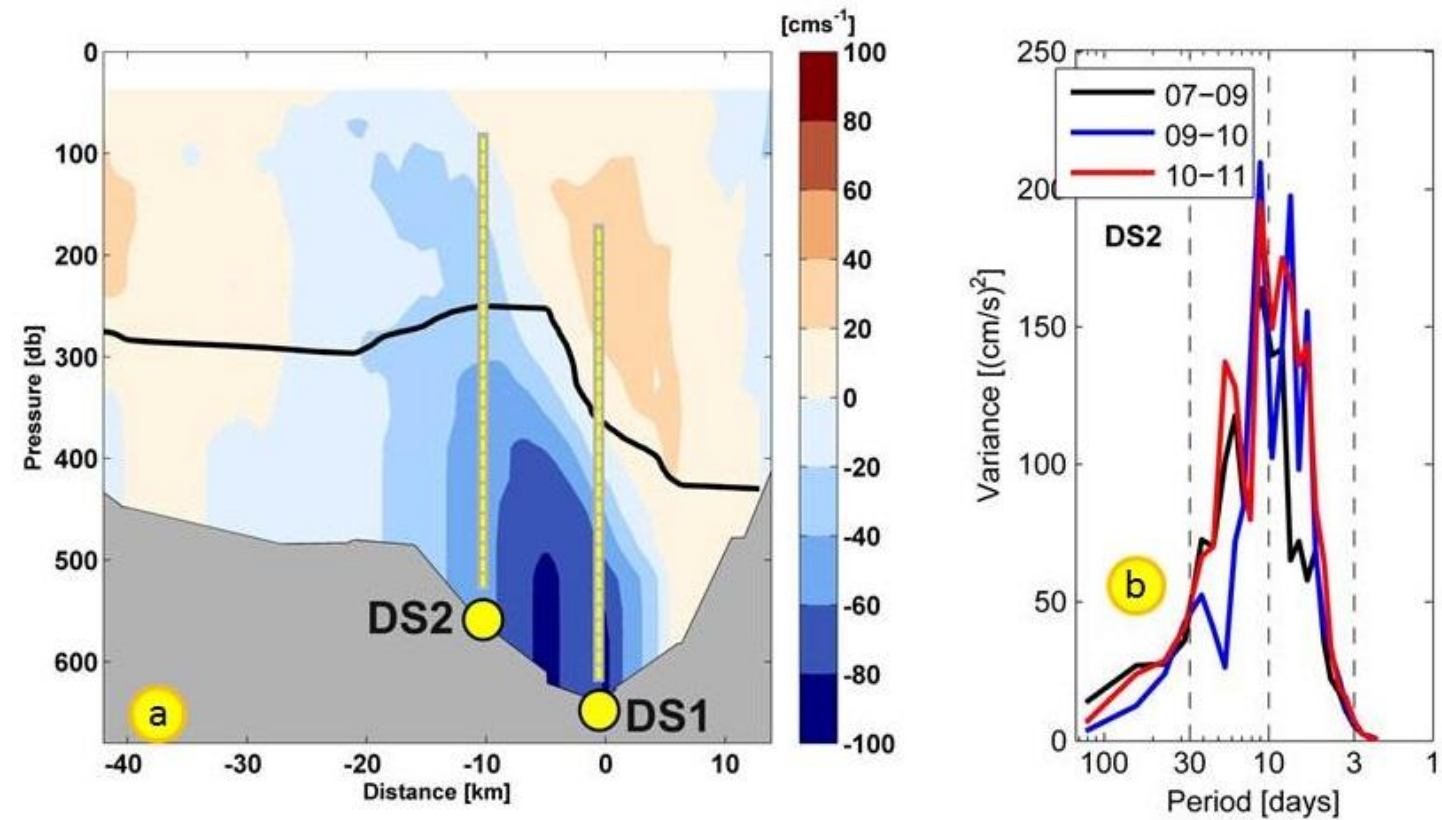

Figure 4: Overflow in Denmark Strait (a), currents in along-channel direction as a snapshot obtained from shipboard ADCP - blue is the Overflow; the heavy black line shows the isopycnal $\sigma_{\theta}=27.8 \mathrm{kgm}^{-3}$. Spectra of the Overflow $(b)$ in the deep current core at Denmark Strait. Data are from moored ADCPs at the depth cell of maximum flow close to the sill depth. For deployment times see figure legend. 


\section{Figure 5}
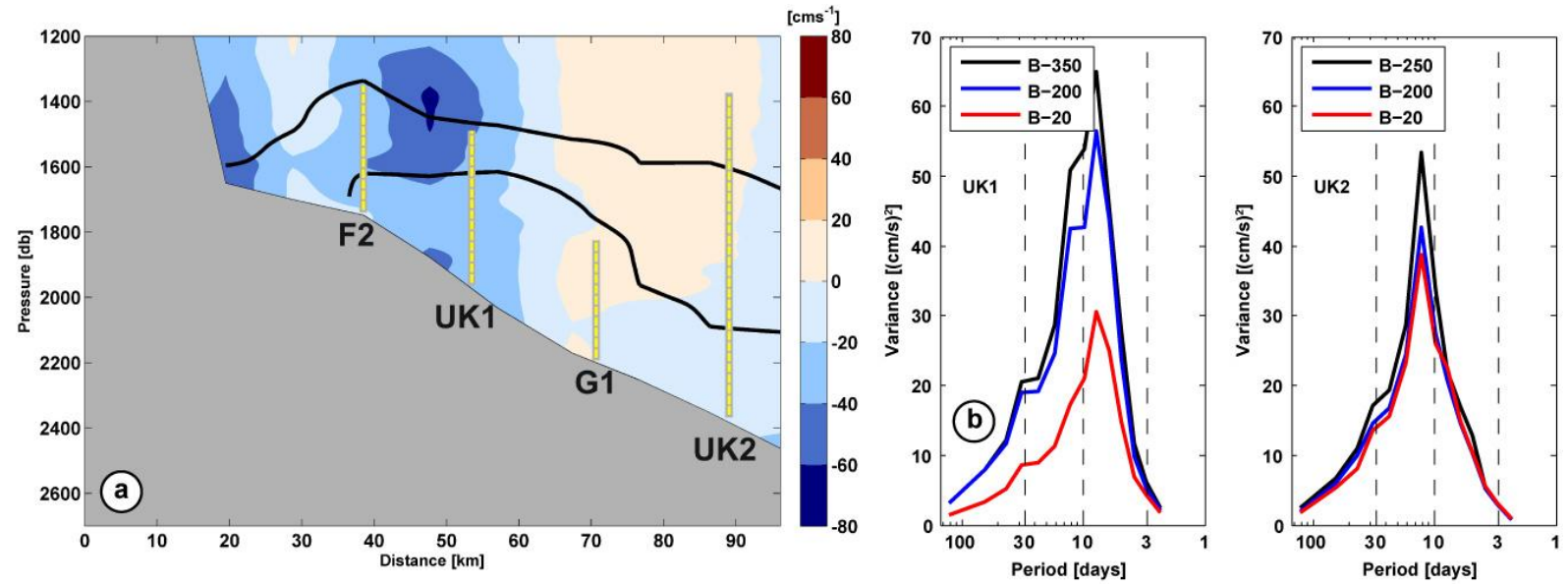

Figure 5: a) Snapshot of cross-section velocity from lowered ADCP data, as measured in July 2010 during cruise Meteor M82-1. Negative velocities are toward the southwest (blue), while positive velocities are northeastward (red). Two isopycnals are included in black: $\sigma_{\theta}=$ $27.8 \mathrm{kgm}^{-3}$ as the upper boundary of the overflow components, and $\sigma_{\theta}=27.85 \mathrm{kgm}^{-3}$ as the upper Denmark Strait Overflow plume. The $x$-axis gives the distance starting on the Greenland shelf. The recent Angmagssalik array is illustrated in yellow.

b) Spectra from the Angmagssalik array. Only near bottom records are shown; the depth above bottom is given in the figure legend (B-XXX). Left: Spectra from UK1 at $1980 \mathrm{~m}$ water depth, and a record length of 4 years. The record to the right (UK2 at $2350 \mathrm{~m})$ is very long (almost 7 years) and it shows a very narrow spectral peak at 8-12 day periods. 


\section{Figure 6}
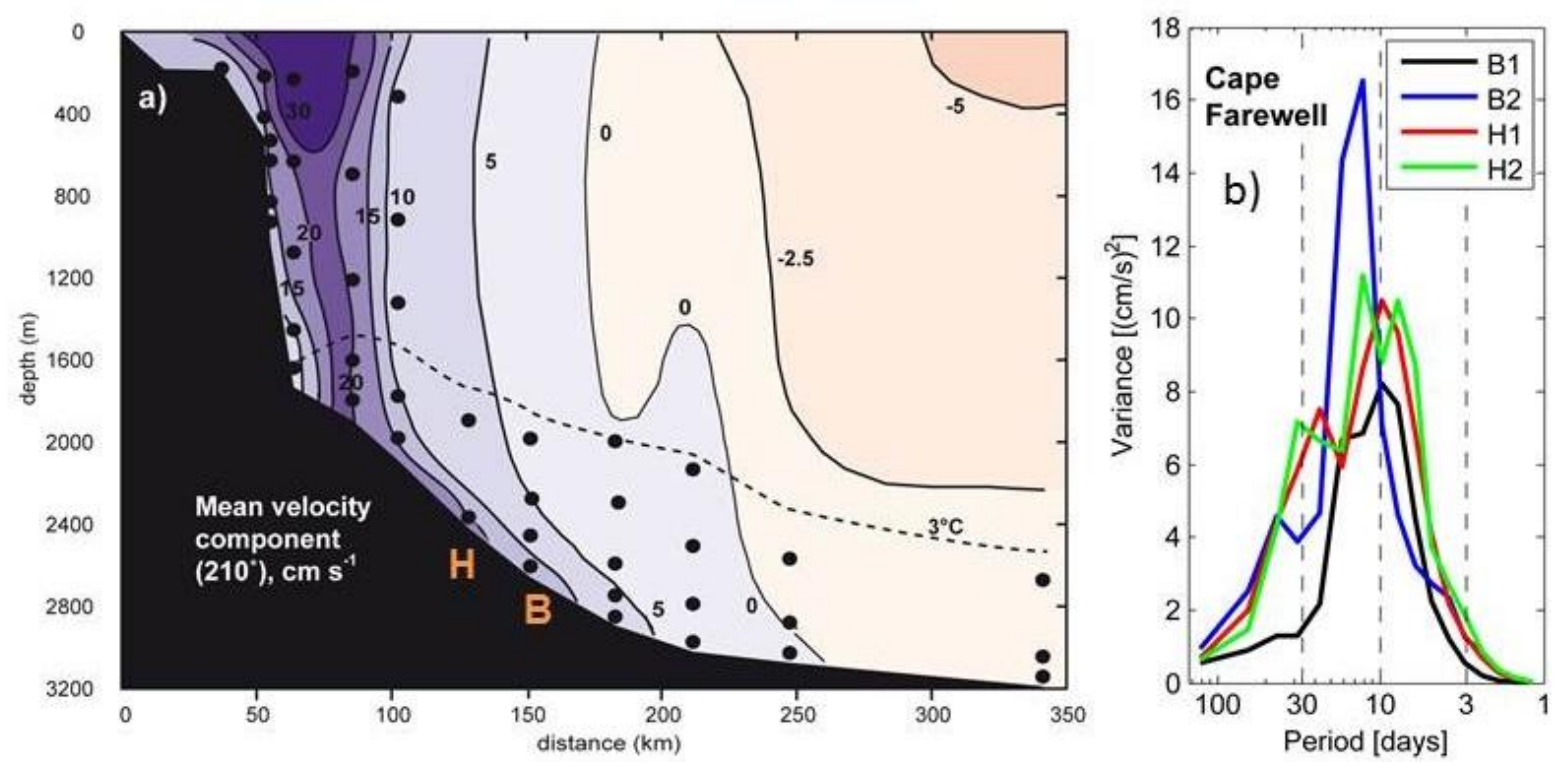

Figure 6: The Cape Farewell array. a) Mean velocity cross-array flow (cm/s) and mean depth of the $3^{\circ} \mathrm{C}$ isotherm; b) Spectra from the deepest instruments at moorings $B$ and $H$ in the core of the $D W B C$ and below the $3^{\circ} \mathrm{C}$ isotherm which in this case represent the upper limit of the overflow waters. Instrumental depth of $\mathrm{HI}$ and $\mathrm{H} 2$ are 1900m and 2370m; BI and B2 are $1980 m$ and $2450 m$, respectively. 


\section{Figure 7}
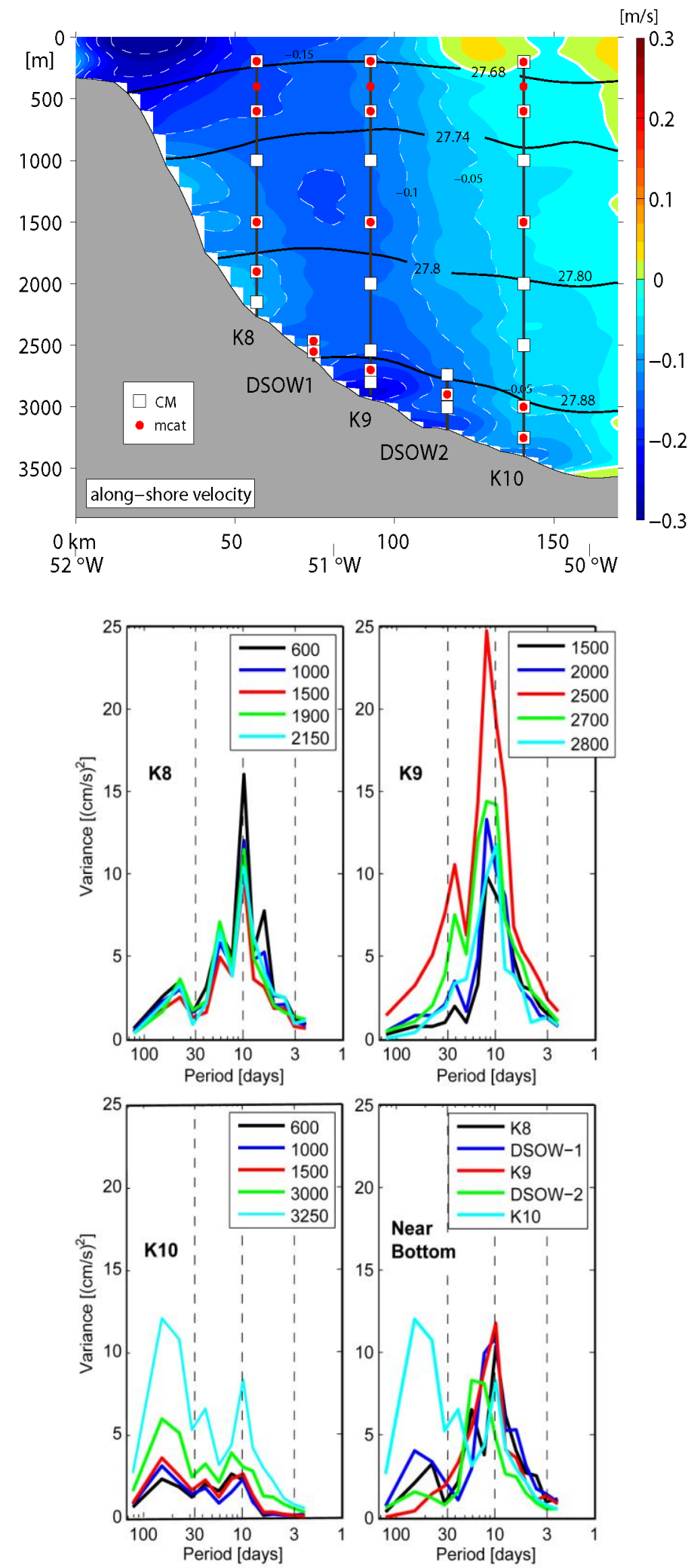

Figure 7: The current meter array at $53^{\circ} \mathrm{N}$ (top) at the exit of the Labrador Sea in its current configuration; in the background the mean boundary current from all available LADCP section (1997 to 2010) data. Alongshore currents were de-tided before calculating varianceconserving spectra shown in the 4 panels below. Spectra of the three core moorings $(K 8, K 9$ 
and $\mathrm{K} 10$ ) of the $53^{\circ} \mathrm{N}$ array all show the spectral peak at periods of 10-12 d through all depth levels. Near-shore at $K 8$ the highest variance is near the surface layer. In the center of the DWBC (mooring K9) the DSOW core has highest variance and similarly at K10, but at strongly reduced amplitudes. The lower right graph shows the variance-conserving spectra of the near bottom flow at $53^{\circ} \mathrm{N}$ with maximum variance in the DSOW core at mooring K9 in the center of the array.

\section{Figure 8}
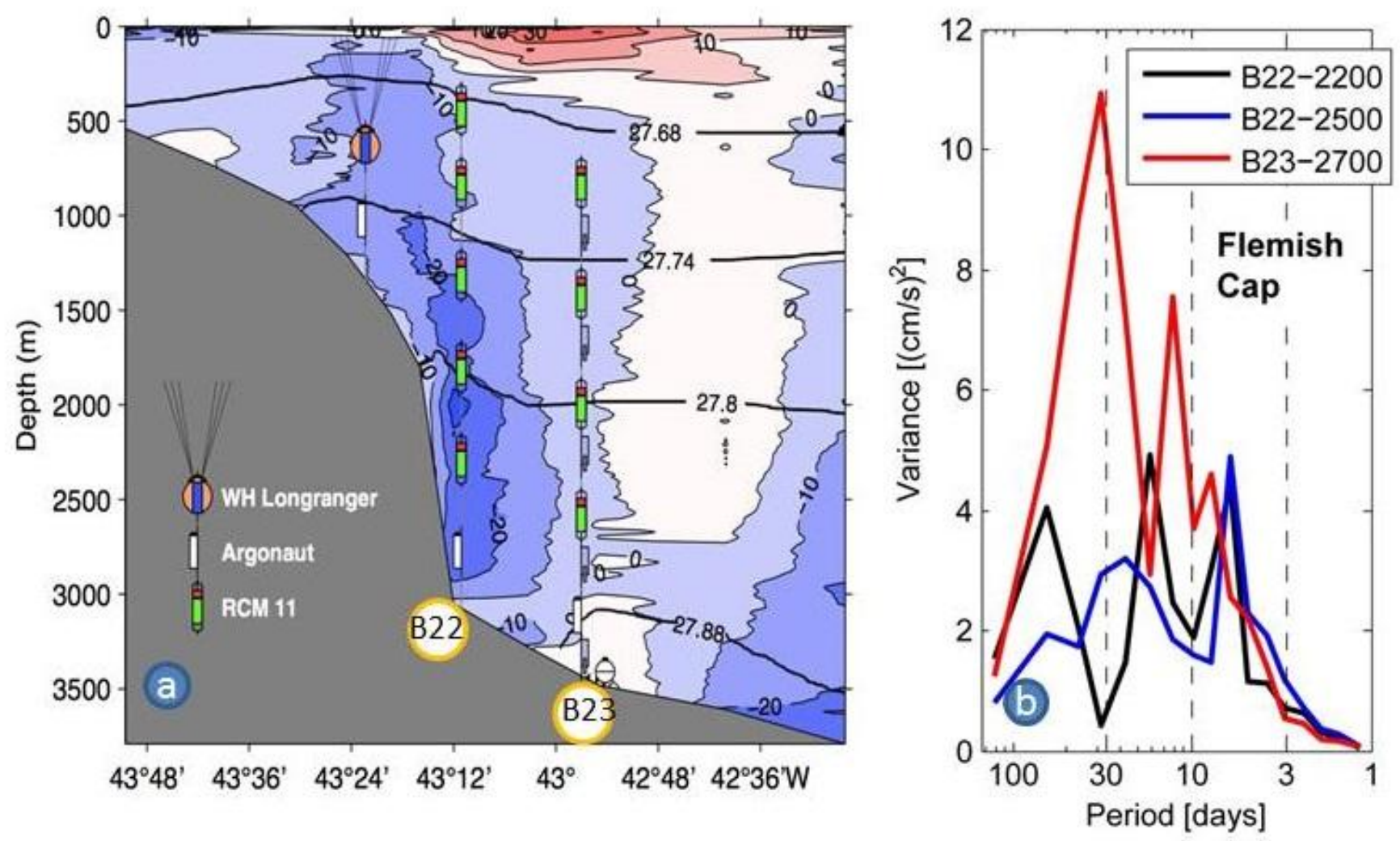

Figure 8: Distribution of instruments in the Flemish Cap mooring array. Mooring B22 is in the center, and B23 is located at the easternmost location, the moorings consist of several versions of acoustic current meters. The meridional velocity (blue: southward, red: northward) from lowered ADCP as observed in summer 2008 is used as a background. The black lines denote isopycnals used as deep water mass boundaries (left). Velocity spectra (right) of the three deep records in moorings B22 and B23 below the density surface $\sigma_{\theta}>$ $27.80 \mathrm{kgm}^{-3}$. The time series are up to 3 years long. 


\section{Figure 9}
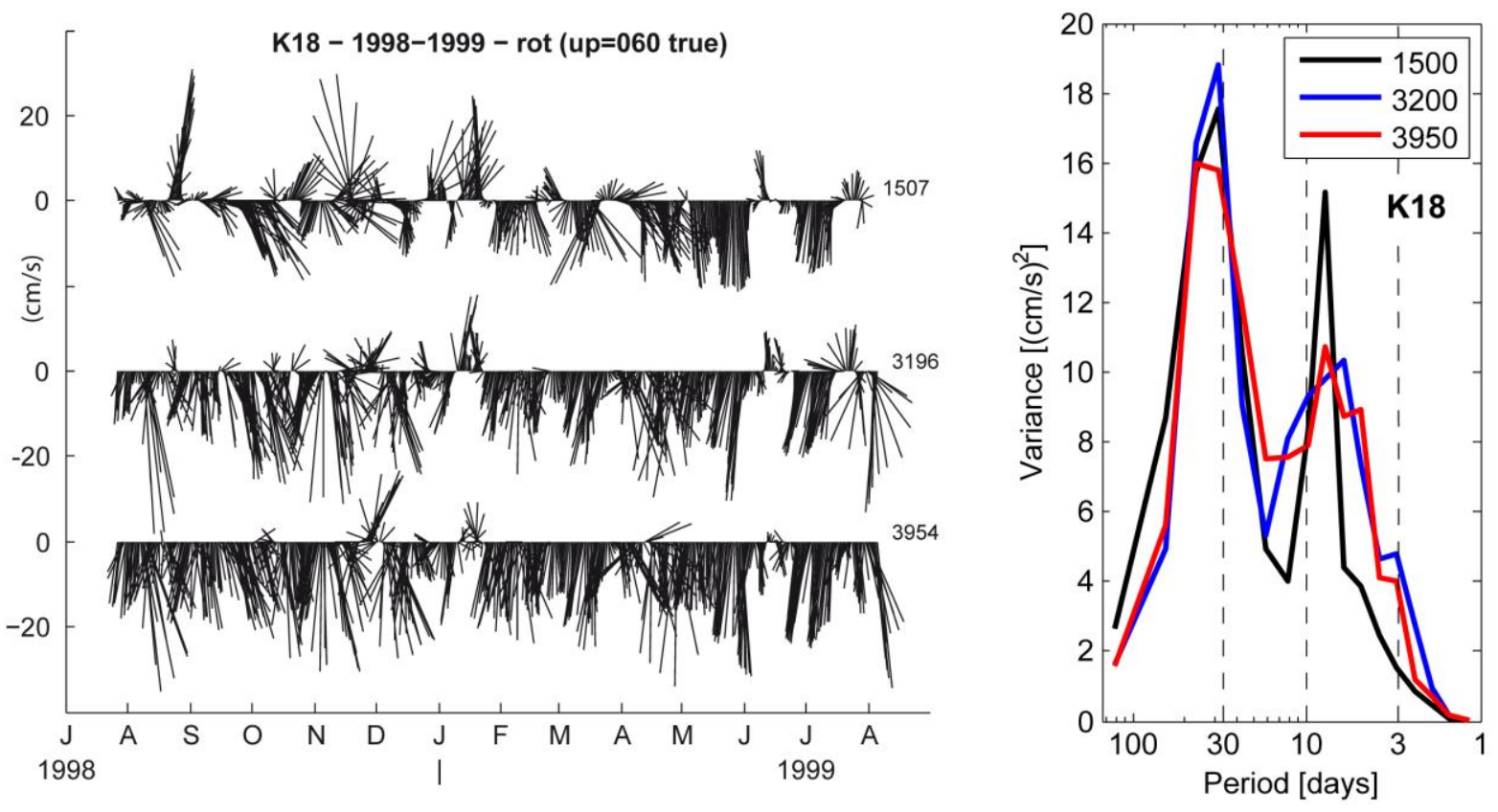

Figure 9: Currents at Flemish Cap from the mooring deployed 1998-1999 as a "stick plot" (left) with currents rotated to $60^{\circ}$ true, such that flow along the topography is downward. Spectra of the time series (right). 


\section{Figure 10}
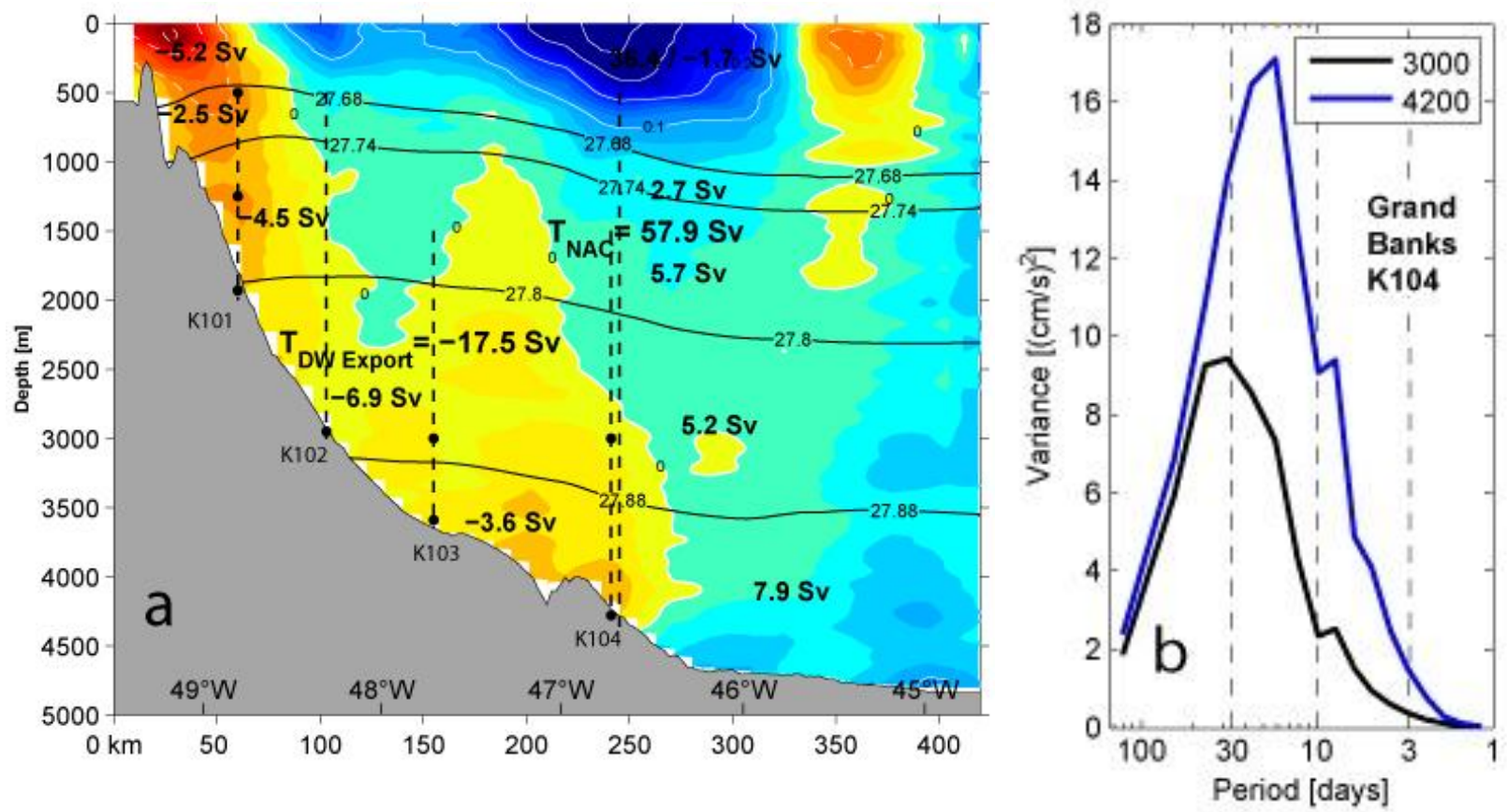

Figure 10: a) Mean ship section of ADCP/LADCP currents parallel to the topography of the Grand Banks (after Schott et al. 2006), composed from four cruises in summers of 1999, 2001, 2002 and 2005. DWBC flows southward along the boundary, NAC flows northward offshore. Transports are given in density layers corresponding to the different NADW water masses.

b) Spectra from the Grand Banks mooring K104. Note, the variance increases toward the bottom, and maximum energy is found around the period of 30 days. 


\section{Figure 11}

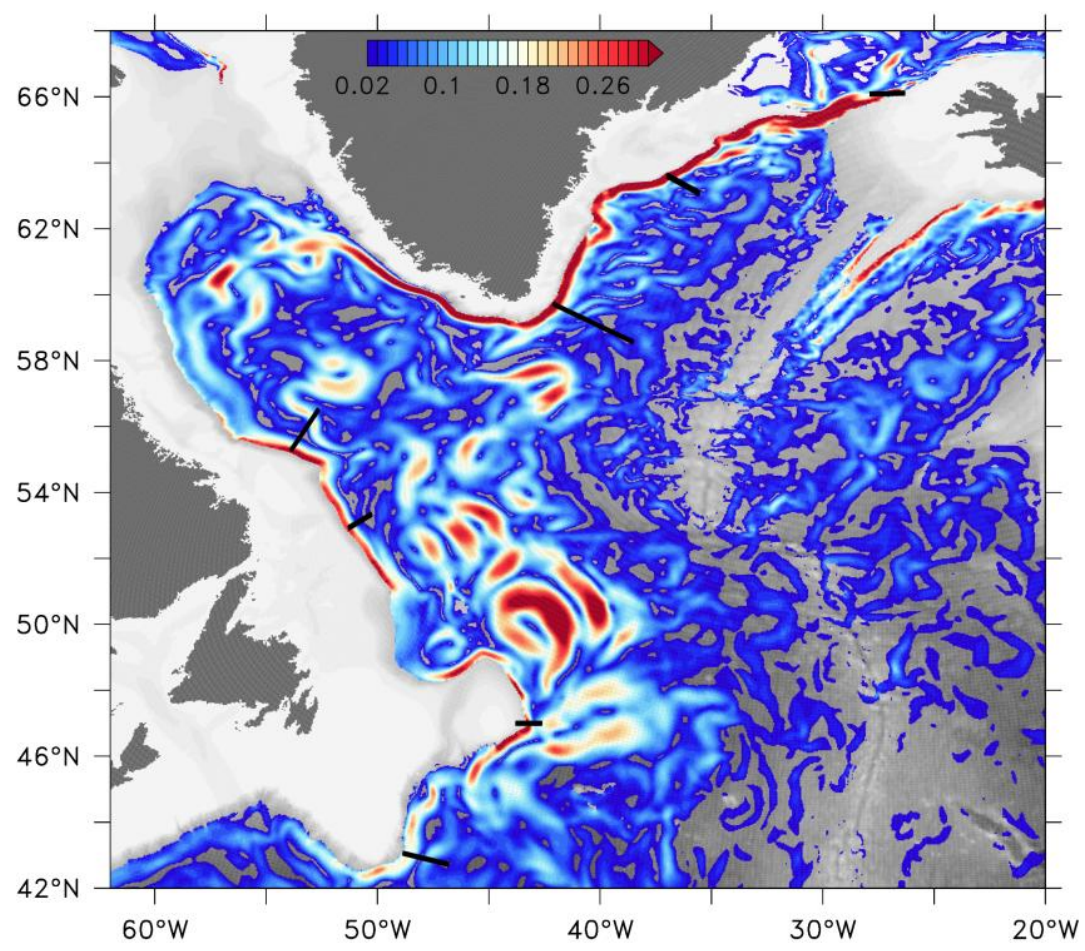

Figure 11: Model snapshot of the current speed along $\sigma_{\theta}=27.85 \mathrm{~kg} \mathrm{~m}^{-3}$ representing the upper limit of the DSOW layer. For model / observation comparisons the location of the investigated variability are indicated as black lines; color bar for currents in $\mathrm{ms}^{-1}$. 


\section{$\underline{\text { Figure } 12}$}
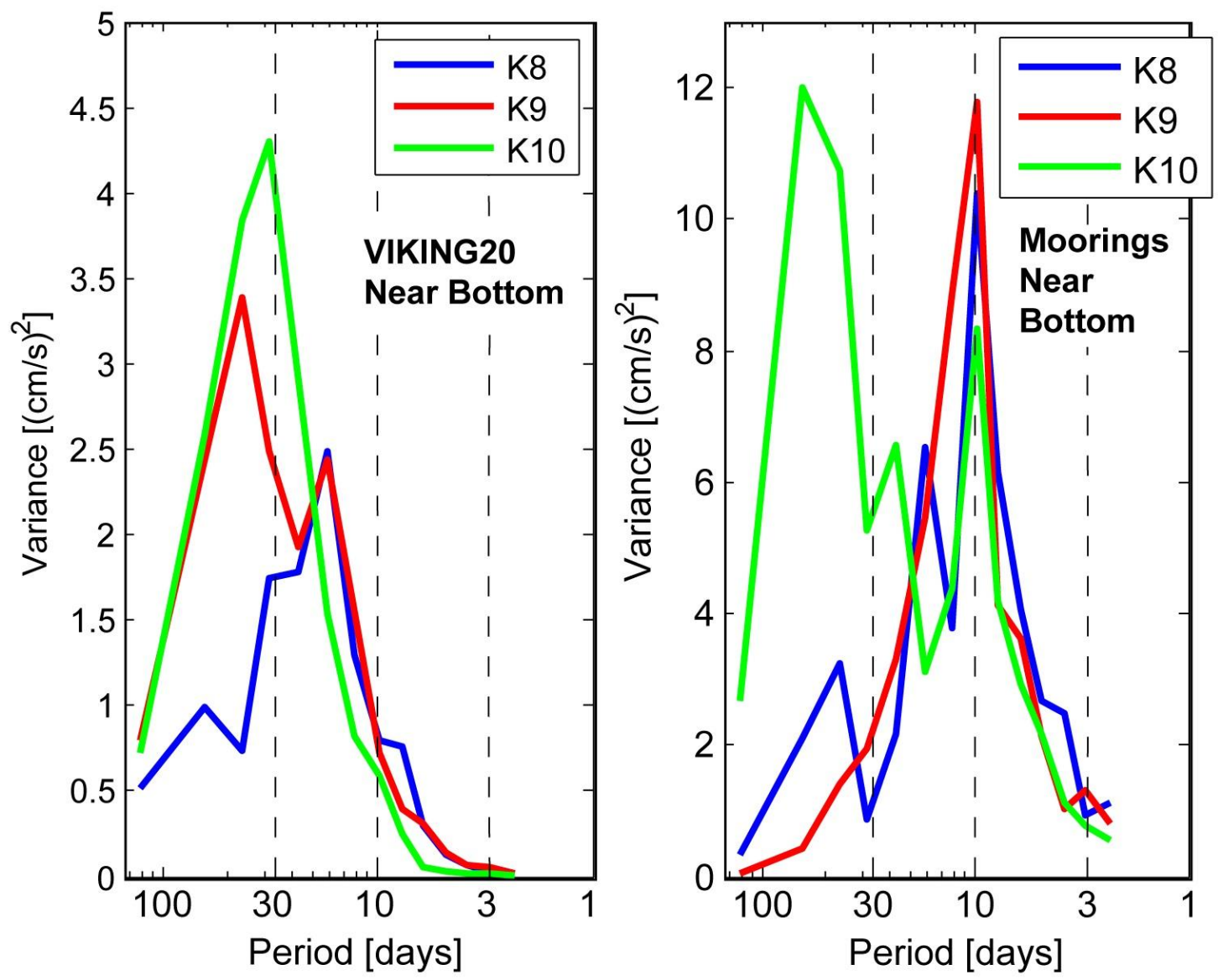

Figure 12: Model (left) and observed (right) spectra of the alongshore flow at $53^{\circ} \mathrm{N}$ at the locations of moorings K8, K9, and K10. For illustration the main frequencies (periods of $3 d$, $10 \mathrm{~d}$ and 30d) are marked by dashed vertical lines. Data are from the near bottom instruments and corresponding grid cells of the model - variance scaling is different as observed variance is significantly larger. 


\section{Figure 13}
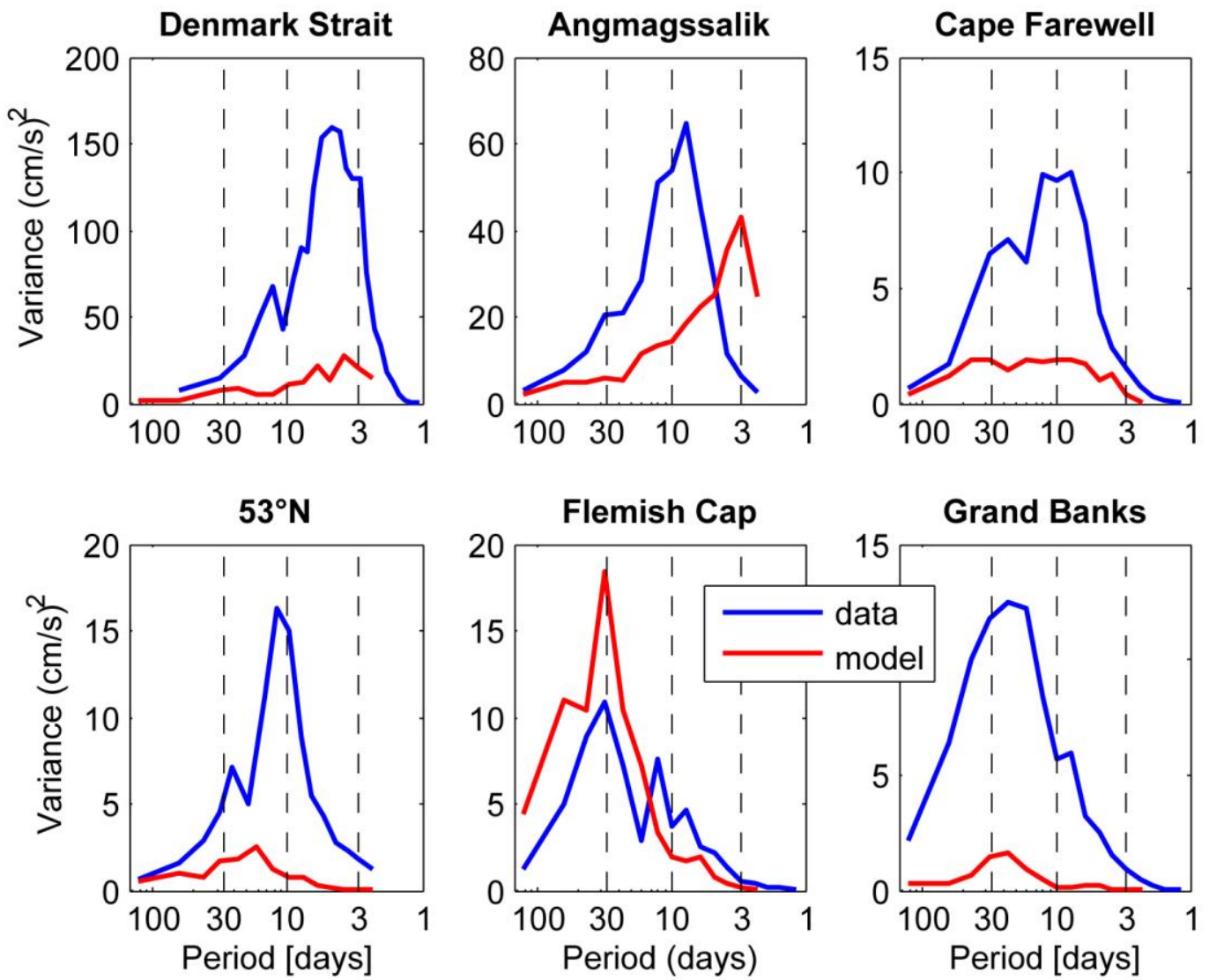

Figure 13: Spectral comparison of intra-seasonal variance. Observed spectra in blue, modeled spectra are in red. The axes are scaled differently due to the very different variance levels in some places dashed lines at 3,10 and 30 days for orientation purposes. 


\section{Figure 14}
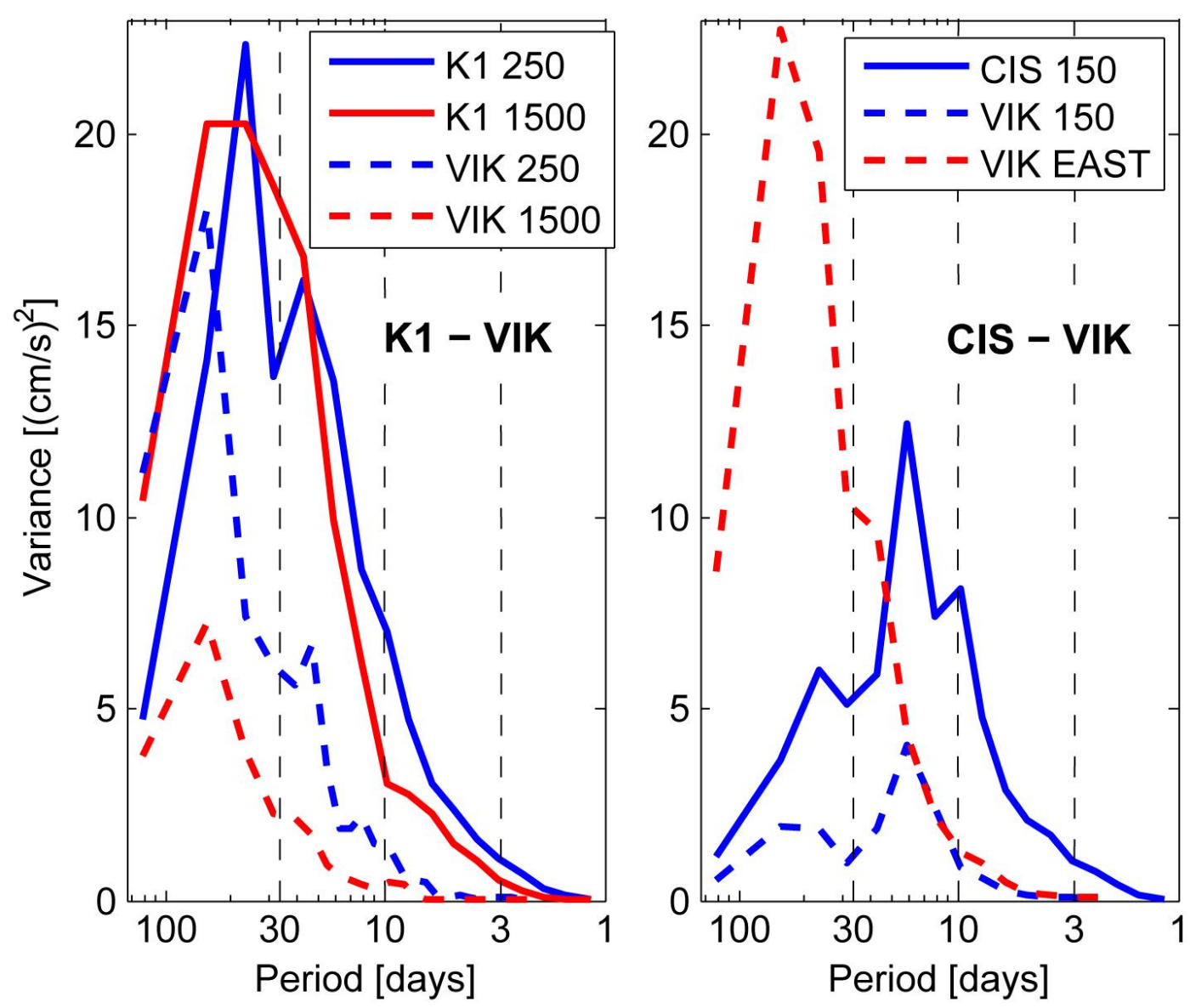

Figure 14: Intra-seasonal variance (V-component) in the central Labrador Sea (left, mooring $K 1$ and the model spectra) at two levels, $250 \mathrm{~m}$ depth measured by an ADCP, and at $1500 \mathrm{~m}$ (LSW layer) by a single point current measurement (rotor or acoustic current meter). Similarly we calculated a spectrum of the near surface variance in the Central Irminger Sea (CIS mooring) compared to variance spectra of the VIKING20 model at the CIS location and farther to the east in the center Irminger Sea (dashed red). 


\section{Figure 15}
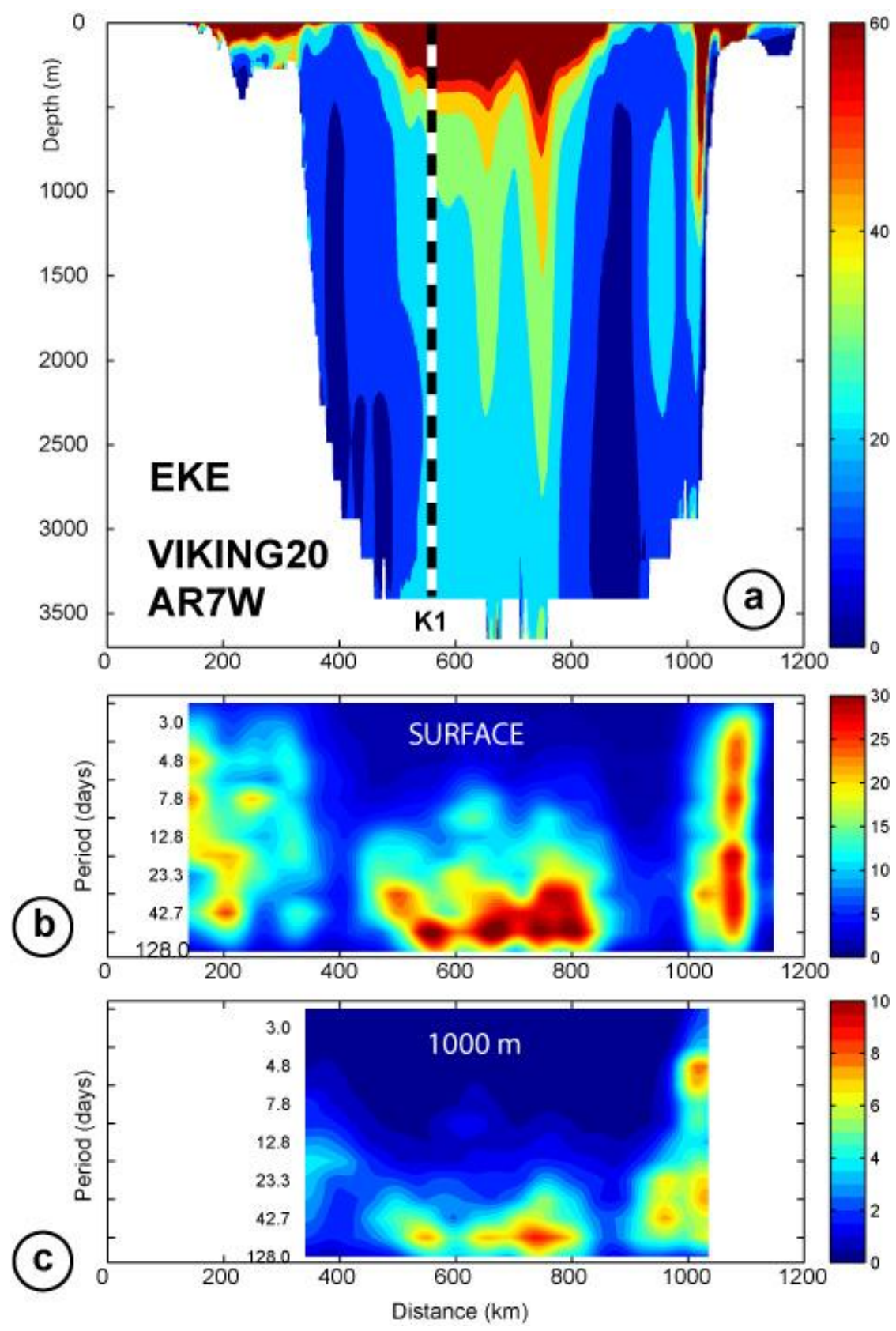

Figure 15: a) EKE distribution along the AR7W section from the 2-year long run of VIKING20; indicated is the position of mooring K1. b) Model spectral variance in $1000 \mathrm{~m}$ depth and at the surface, and c) variance in 1000m depth along WOCE section AR7W (for 
location see Figure 1. Spectral Amplitude is shown by color and is plotted for individual frequency (period) bands; note the different variance scale.

\section{Figure 16}
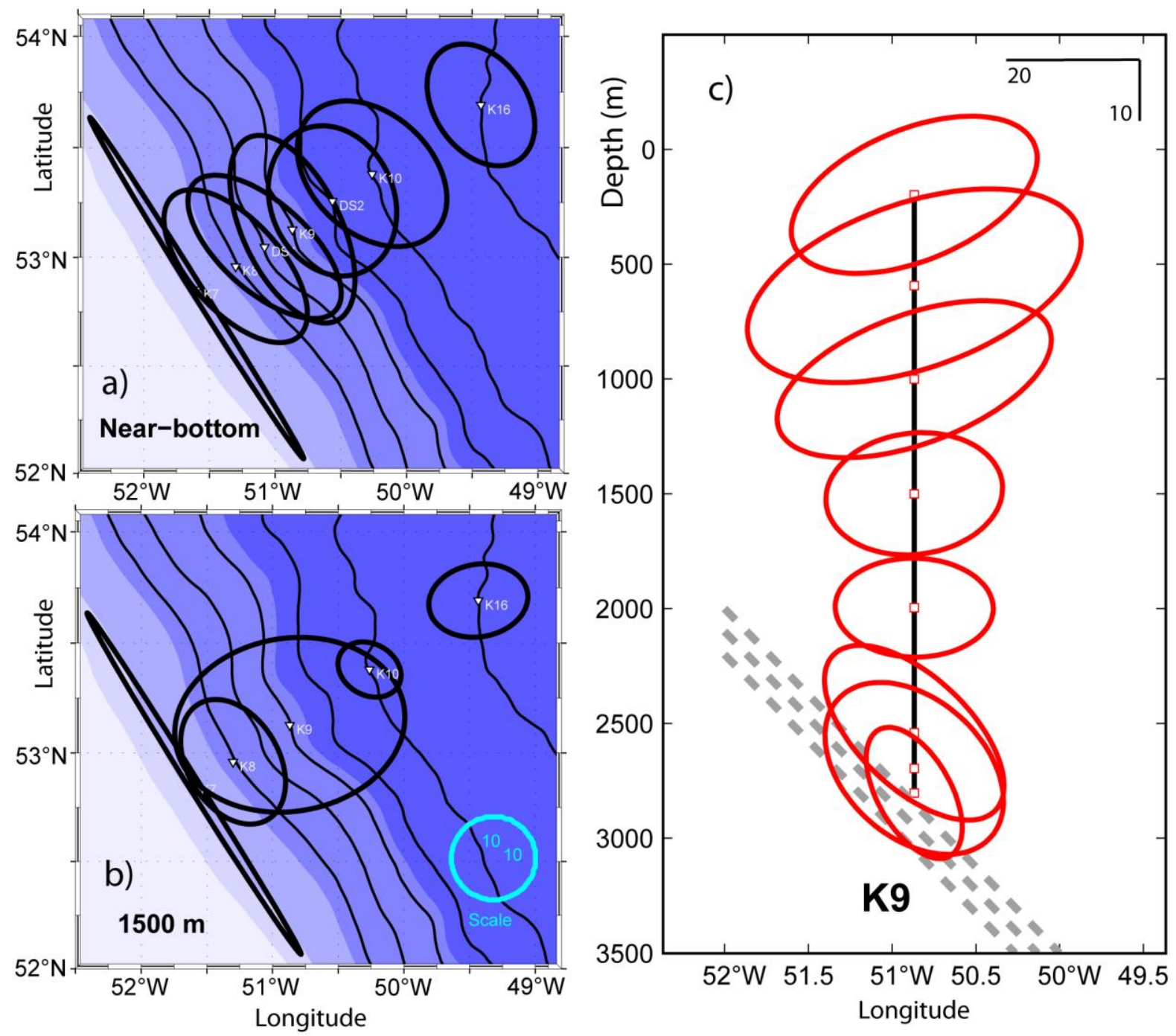

Figure 16: Variance ellipses at the $53^{\circ} \mathrm{N}$ array; (a) intra-seasonal variance ellipses measured close to the bottom (units are $\left.\mathrm{cm}^{2} \mathrm{~s}^{-2}\right) ;(b)$ the same, but for the $1500 \mathrm{~m}$ level (LSW layer); and (c) vertical structure of variance ellipses at mooring $K 9$ in the center of the array. Bottom topography is from the 2' ETOPO data set and smoothed over a 10nm length scale; in Fig. 16c, the orientation of isobaths at K9 is indicated by dashed lines. All data were high pass filtered at 60d cut-off periods. 


\section{$\underline{\text { Figure } 17}$}

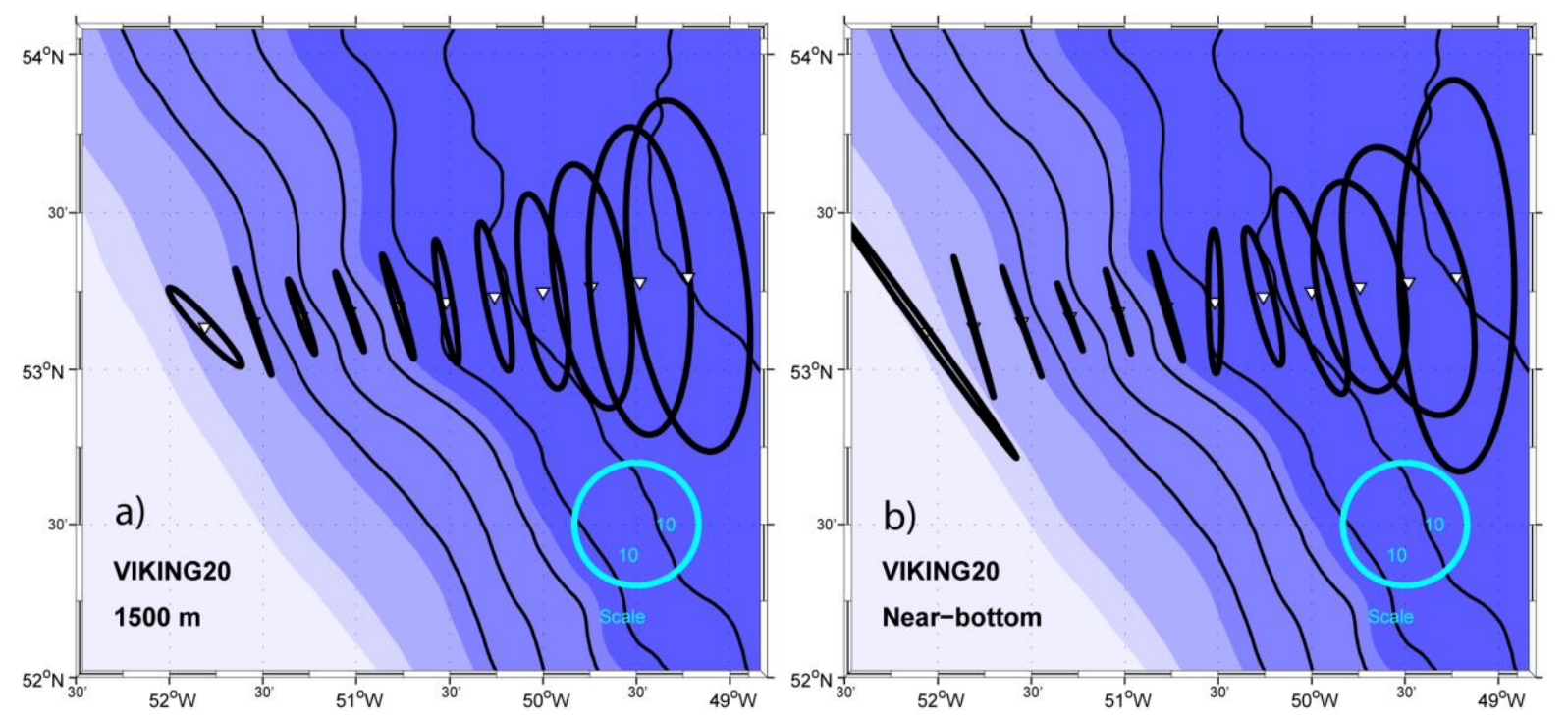

Figure 17: Variance ellipses as in Figure 17, but for model data near the $53^{\circ} \mathrm{N}$ mooring locations. 


\section{Figure 18}

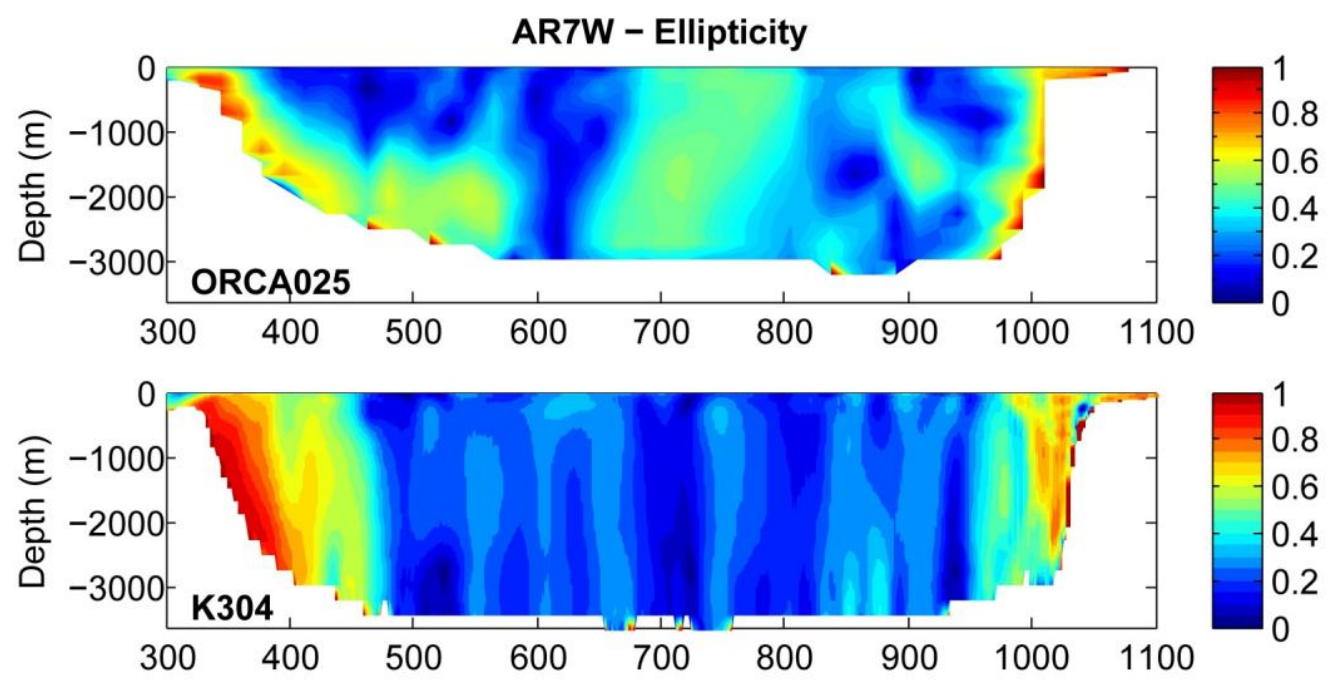

Figure 18: Ellipticity of the flow at the AR7W section across the Labrador Sea and between the shelf break of Labrador (left) to that of Greenland. Top graph is from a run of a model that has $1 / 4^{\circ}$ resolution and the lower graph is from the VIKING20 model. 


\section{Figure 19}

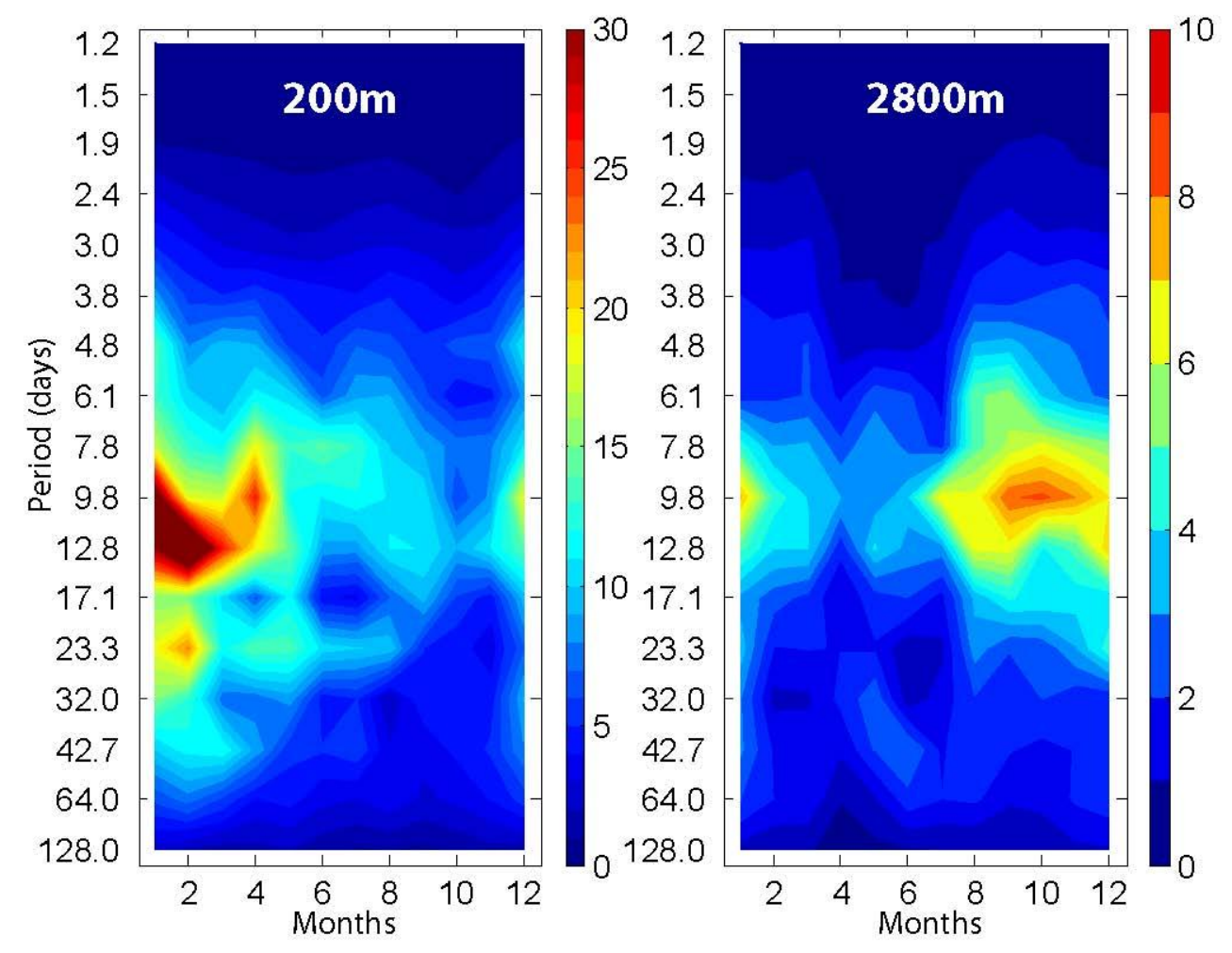

Figure 19: Seasonal distribution of intra-seasonal variance. Spectral band (periods in days) is plotted versus time (month) of year. Data are from K9 near the surface (left) and near the bottom in the DSOW layer (right). Color bar is different from 0 to $30 \mathrm{~cm}^{2} \mathrm{~s}^{-2}$ and from 0 to 10 $\mathrm{cm}^{2} \mathrm{~s}^{-2}$. 